\title{
Monetary Policy Implementation with an Ample Supply of Reserves
}

\author{
Gara Afonso, Kyungmin Kim, Antoine Martin, \\ Ed Nosal, Simon Potter, and Sam Schulhofer-Wohl
}

\author{
Working Paper 2020-2 \\ January 2020
}

\begin{abstract}
Methods of monetary policy implementation continue to change. The level of reserve supplyscarce, abundant, or somewhere in between-has implications for the efficiency and effectiveness of an implementation regime. The money market events of September 2019 highlight the need for an analytical framework to better understand implementation regimes. We discuss major issues relevant to the choice of an implementation regime, using a parsimonious framework and drawing from the experience in the United States since the 2007-09 financial crisis. We find that the optimal level of reserve supply likely lies somewhere between scarce and abundant reserves, thus highlighting the benefits of implementation with what could be called "ample" reserves. The Federal Reserve's announcement in 0ctober 2019 that it would maintain a level of reserve supply greater than the one that prevailed in early September is consistent with the implications of our framework.
\end{abstract}

JEL classification: E42, E58

Key words: federal funds market, monetary policy implementation, ample reserve supply

https://doi.org/10.29338/wp2020-02

Potter worked on this paper while he was at the Federal Reserve Bank of New York and not subsequently. The authors thank Jim Clouse, Spence Krane, Laura Lipscomb, Julie Remache, Zeynep Senyuz, Nate Wuerffel, and Patricia Zobel for useful comments. The views expressed here are those of the authors and not necessarily those of the Federal Reserve Banks of New York, Atlanta, and Chicago; the Board of Governors; or the Federal Reserve System. Any remaining errors are the authors' responsibility.

Please address questions regarding content to Gara Afonso, Federal Reserve Bank of New York, gara.afonso@ny.frb.org; Kyungmin Kim, Federal Reserve Board of Governors, kyungmin.kim@frb.gov; Antoine Martin, Federal Reserve Bank of New York, antoine.martin@ny.frb.org; Ed Nosal, Federal Reserve Bank of Atlanta, ed.nosal@atl.frb.org; Simon Potter, Peterson Institute for International Economics; or Sam Schulhofer-Wohl, Federal Reserve Bank of Chicago, samuel.schulhoferwohl@chi.frb.org.

Federal Reserve Bank of Atlanta working papers, including revised versions, are available on the Atlanta Fed's website at www.frbatlanta.org. Click "Publications" and then "Working Papers." To receive e-mail notifications about new papers, use frbatlanta.org/forms/subscribe. 


\title{
Monetary policy implementation with an ample supply of reserves
}

\author{
Gara Afonso, Kyungmin Kim, Antoine Martin, \\ Ed Nosal, Simon Potter, and Sam Schulhofer-Wohl ${ }^{1}$
}

\begin{abstract}
Methods of monetary policy implementation continue to change. The level of reserve supplyscarce, abundant, or somewhere in between - has implications for the efficiency and effectiveness of an implementation regime. The money market events of September 2019 highlight the need for an analytical framework to better understand implementation regimes. We discuss major issues relevant to the choice of an implementation regime, using a parsimonious framework and drawing from the experience in the United States since the 2007-2009 financial crisis. We find that the optimal level of reserve supply likely lies somewhere between scarce and abundant reserves, thus highlighting the benefits of implementation with what could be called "ample" reserves. The Federal Reserve's announcement in October 2019 that it would maintain a level of reserve supply greater than the one that prevailed in early September is consistent with the implications of our framework.
\end{abstract}

Keywords: federal funds market, monetary policy implementation, ample reserve supply JEL classification: E42, E58

\footnotetext{
${ }^{1}$ Afonso and Martin, Federal Reserve Bank of New York; Kim, Board of Governors; Nosal, Federal Reserve Bank of Atlanta; Schulhofer-Wohl, Federal Reserve Bank of Chicago; Potter, Peterson Institute for International Economics. Potter worked on this paper while he was at the Federal Reserve Bank of New York and not subsequently. We thank Jim Clouse, Spence Krane, Laura Lipscomb, Lorie Logan, Julie Remache, Zeynep Senyuz, Nate Wuerffel, and Patricia Zobel for useful comments. The views expressed herein are those of the authors and may not represent the views of the Federal Reserve Banks of New York, Atlanta, and Chicago, the Board of Governors, or the Federal Reserve System.
} 


\section{Introduction}

Monetary policy implementation is the process by which a central bank conducts operations and sets administered rates to transmit the desired stance of monetary policy to financial markets and the real economy. Much of monetary economics abstracts from policy implementation and simply assumes that the central bank can effortlessly establish any policy stance it desires. Yet, in practice, the challenges of implementing policy can constrain the set of feasible policy stances - and, in turn, the choice of a policy stance can influence how policy must be implemented.

The 2007-2009 financial crisis and its aftermath highlighted these interactions. In many advanced economies, conventional rules called for a negative nominal policy rate in response to the extreme shock of the crisis. Yet in an economy with physical currency, it can be challenging to implement a deeply negative nominal interest rate. This implementation problem drove many major central banks to adopt unconventional policy tools, such as forward guidance and largescale asset purchases. In turn, asset purchases resulted in central banks changing their overall frameworks for controlling short-term interest rates: Pre-crisis, these frameworks were typically based on adjusting the scarcity value of a limited supply of central bank deposits (reserves), but the substantial increase in liquidity resulting from asset purchases in response to the crisis made other techniques necessary.

Today, as some central banks unwind their responses to the financial crisis and normalize their policy stances, methods of monetary policy implementation continue to change. Central banks are reviewing what they have learned since the crisis and considering whether they want to continue using the implementation frameworks that they adopted post-crisis, return to their precrisis methods, or transition to other methods entirely.

In this paper, we develop a model that can be used to classify central bank operating regimes based on the level of reserves in the banking system and the slope of the reserve demand curve. Throughout the paper, we consider the experience of the Federal Reserve to create a link between theory and practice. We build our model on the foundation of the classic Poole (1968) model of reserve demand. In this model, banks demand reserves only to meet reserve requirements, and there are no frictions in the interbank market. These and other assumptions give the demand curve a simple shape, illustrated in Figure 1: At high levels of aggregate reserves, demand is flat, with banks indifferent among a wide range of reserve holdings as long as market rates equal the interest rate paid on reserves; at lower levels of aggregate reserves, demand is steeply sloped because reserves have a scarcity value; and these two regions meet at a sharp kink. We then extend the model to include post-crisis changes in the sources of reserve demand and in the functioning of the interbank market. Interbank frictions give the aggregate demand curve a smoother shape - still steeply sloped at very low levels of reserves and flat at very high levels of reserves, but connected by an intermediate region where demand has a gentle slope. One interpretation of our model is that reserves could be called abundant when the aggregate demand curve is flat and scarce when the aggregate demand curve has a steep negative slope. In between scarcity and abundance, where the aggregate demand curve has a gentle downward slope, we could say that reserves are ample. We emphasize that these labels are ours and that others may have different interpretations. 


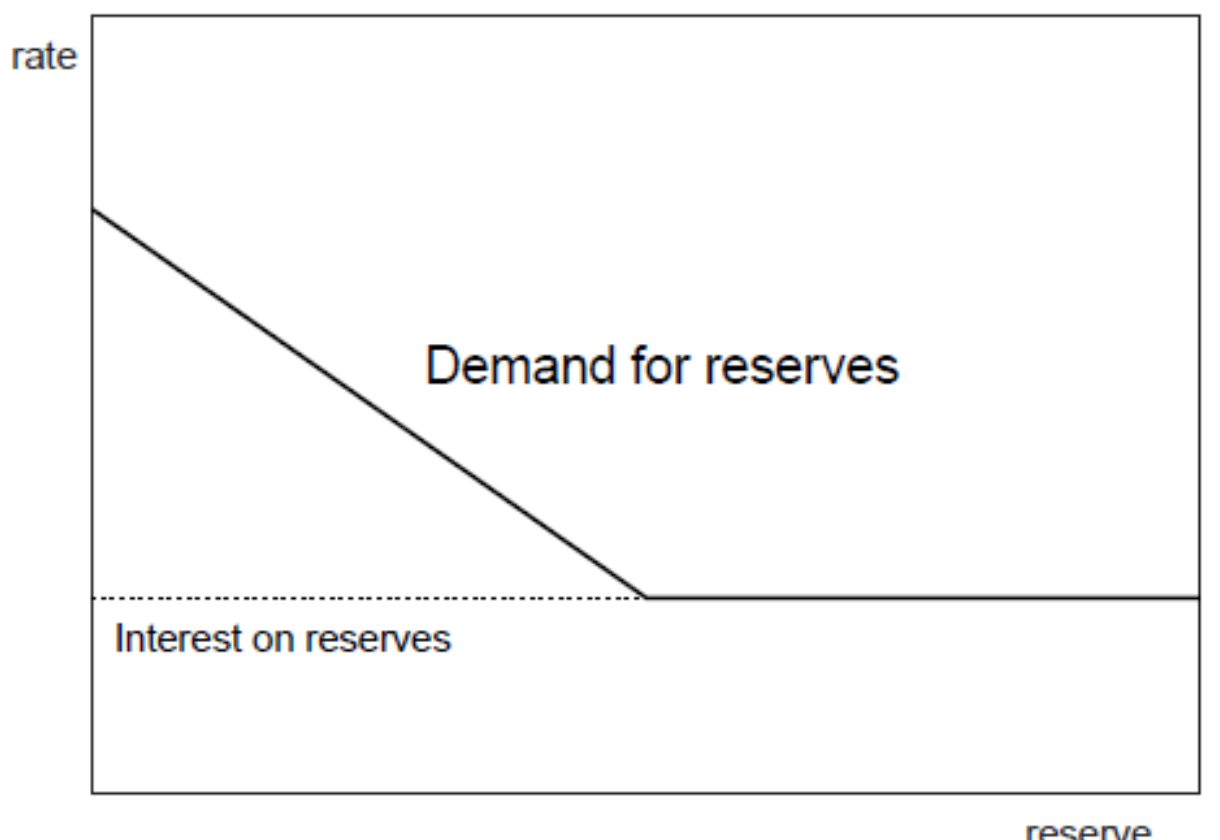

Figure 1: Reserve Demand in the Poole Model.

Next, we review how a central bank can influence money market rates in these different regimes. At lower levels of reserves, where the demand curve is more steeply sloped, adjustments in reserve supply can move money market rates by changing the scarcity value of reserves. At higher levels of reserves, where the demand curve has less or no slope, adjustments in administered interest rates become the main tool for moving money market rates.

When a central bank faces shocks to reserve supply and demand, these differences in regimes create a tradeoff between the size of the central bank's balance sheet and interest rate volatility, as well as the frequency of open market operations. The tradeoff is especially important when shocks to reserve supply are large, which, as we show in section 3 , has been a notable feature of the post-crisis environment. The money market events of mid-September 2019 suggest that this tradeoff is relevant in practice.

In section 4, we present a parsimonious theoretical framework for finding an optimal level of reserve supply given the tradeoffs between balance sheet size, interest rate volatility, and frequency of operations. The optimal level of reserve supply balances the regime's effectiveness - namely, its ability to control the policy interest rate - against the regime's efficiency, measured by the frequency of operations and the size of the central bank's balance sheet.

This framework for thinking about reserve supply is consistent with the Federal Reserve's announcement in January 2019 that it plans to remain in a regime of "ample reserves," where administered interest rates such as the rate paid on reserves are the primary implementation tool 
and where active adjustments in reserve supply are not needed to implement policy. ${ }^{2}$ It is also consistent with the Federal Reserve's longstanding plan to operate with a balance sheet that is no larger than necessary for efficient and effective policy implementation. ${ }^{3}$

We also discuss how the Federal Reserve's decision on reserve levels in October 2019 can be interpreted within our framework. Our analysis focuses on the federal funds market, since the Federal Open Market Committee (FOMC) establishes the stance of policy by setting a target range for the federal funds rate. As such, we do not attempt to present a complete account of dynamics across all money markets.

Section 5 broadens the consideration of effectiveness to money markets in general. We examine the operating regime's ability to provide control over short-term money market rates, as measured both by dispersion across these rates and by the pass-through of administered rates to market rates. We find that, so far, the evidence suggests a high degree of effectiveness for the Federal Reserve's current regime.

Finally, considering the broader context of the entire financial system, we argue that financial stability concerns may make it socially efficient for the central bank to supply ample reserves rather than make reserves scarce. In particular, an important contrast between implementation mechanisms with ample reserves and the pre-crisis mechanism of adjusting reserve supply to change the scarcity value of reserves is that a regime operating mainly through adjustments in administered rates can exert influence on money market rates even after large reserve injections such as those resulting from central banks' responses to the crisis.

\section{A Simple Model of Reserve Demand and Interest Rates}

For many central banks, the policy rate is the rate that banks pay to borrow reserves overnight. Thus a key factor in discussing monetary policy implementation is the relationship between the level of reserves and the overnight interest rate: the aggregate demand curve for reserves. The shape of the demand curve varies across different theoretical models, and our framework is flexible enough to allow a wide variety of shapes.

To motivate the existence of the demand curve and reasonable assumptions on its shape, a good starting point is Poole (1968). In this model, banks must hold reserves overnight to meet reserve requirements, but face random payment shocks during the day that can drain their reserves.

Banks pay a high penalty rate for failing to meet reserve requirements, and earn a lower or zero interest rate on reserve balances in excess of requirements. The lower a bank's reserve holdings at the beginning of the day, the greater risk it faces of paying a penalty and the more it is willing to pay to borrow reserves as a buffer against payment shocks. The same relationship holds for banks in the aggregate. Thus, at lower aggregate levels of reserves, market interest rates increase

\footnotetext{
${ }^{2}$ See "Statement Regarding Monetary Policy Implementation and Balance Sheet Normalization." https://www.federalreserve.gov/newsevents/pressreleases/monetary20190130c.htm.

${ }^{3}$ See "Policy Normalization Principles and Plans," September 2014, available at https://www.federalreserve.gov/monetarypolicy/policy-normalization-discussions-communications-history.htm.
} 
strongly with decreases in the supply of reserves - a relationship that the central bank can use to influence market rates, as we will see later in the paper. At sufficiently high levels of reserves, the demand curve becomes flat at an interest rate equal to the rate paid on excess reserves, and market interest rates become unresponsive to reserve supply, but still respond to changes in the administered rate on excess reserves.

The standard model nicely describes the implementation framework used by many central banks pre-crisis, including the Federal Reserve. Before September 2008, the Federal Reserve would set a target for the effective federal funds rate above the interest rate on excess reserves, which was zero at the time. ${ }^{4}$ Therefore, the target was on the negatively sloped part of the aggregate demand curve. The Federal Reserve would supply the appropriate amount of reserves to intersect the demand curve at the policy target. The amount of total reserves supplied by the Federal Reserve to the banking sector was very small, just under $\$ 9.5$ billion on average in 2006. Excess reserves were approximately $\$ 1.7$ billion. Since banks held reserves primarily to meet reserve requirements, the aggregate demand curve was relatively easy to forecast. As well, the Federal Reserve could reasonably anticipate changes in the aggregate supply of reserves that resulted from changes in the central bank's other liabilities, such as currency in circulation. ${ }^{5}$ As a result, by conducting daily open market operations to offset changes in aggregate supply and demand for reserves, the Federal Reserve could hit its policy target.

In the United States and many other countries, reserve demand and the functioning of the interbank market changed after the financial crisis in at least three important ways. First, changes in liquidity supervision and regulations and bank risk management practices increased the demand for high-quality liquid assets (HQLA), including reserves. Second, reserve demand became more uncertain, at least from the central bank's perspective. Banks can choose how to allocate their HQLA between reserves and government securities, so demand is no longer a static function of regulatory parameters. In addition, even without regulatory changes, the crisis may have changed reserve demand by influencing banks' risk appetites - but this source of demand can change over time and is not easily observable by the central bank. Third, stricter regulations on banks' leverage ratios and balance sheet expansion resulted in increased marginal trading costs in the interbank market, ${ }^{6}$ as did other changes in regulations and risk appetite that indirectly increased banks' perceived cost of trading.

We extend the standard model to reflect these post-crisis changes. The extension generates several important findings. First, the level of reserves needed to implement any given market interest rate is higher because reserve demand is higher. Second, uncertainty about reserve demand leads to uncertainty about the market interest rate that will be associated with any given aggregate level of reserves, but the effect is smaller at higher levels of reserves, where the demand curve is flatter. Third, frictions in the interbank market mean that reserves are not

\footnotetext{
${ }^{4}$ The Financial Services Regulatory Relief Act of 2006 authorized the Federal Reserve Banks to pay interest on balances held by or on behalf of depository institutions at Reserve Banks, subject to regulations of the Board of Governors, effective October 1, 2011. The effective date of this authority was advanced to October 1, 2008, by the Emergency Economic Stabilization Act of 2008.

${ }^{5}$ Footnote: This ability, in part, reflected policies that limited the variability of certain Federal Reserve accounts.

${ }^{6} \mathrm{Kim}$, Martin and Nosal (forthcoming) study the effect of such regulations on the interbank market.
} 
always efficiently distributed, in the sense that banks that have a low marginal value of reserves will not necessarily lend to other banks that have a higher marginal value of reserves. Fourth, at relatively high levels of reserves, the demand curve may have a region with a gentle slope, where changes in reserve supply lead to small - but non-zero - changes in market rates.

We emphasize that our model makes significant simplifying assumptions for clarity of exposition. For example, it focuses on a funding market for similar banks and does not capture differences among banks. Nor does the model describe non-bank borrowers, which are important participants in U.S. money markets but whose costs and constraints often differ from those of banks. Thus, although the model is useful for understanding control of the federal funds rate the policy rate in the U.S. - it does not seek to describe the full range of real-world money market dynamics.

The remainder of this section provides technical details on the model's predictions.

\subsection{Poole (1968) Reserve Demand Model}

A large literature on monetary policy implementation uses some variant of Poole (1968). ${ }^{7}$ This section provides a sketch of the Poole (1968) or standard model. The model assumes that banks demand reserves to meet their regulatory reserve requirements. The central bank provides more than enough reserves to meet these requirements. In other words, aggregate excess reserves - the difference between total reserves and required reserves - are strictly positive.

Banks can adjust their reserve holdings in an interbank market which, for the time being, is assumed to be competitive and frictionless. After the interbank market closes, banks receive a payment shock that reallocates reserves among them. If a bank's payment shock is sufficiently negative, its reserve holdings will fall below what is required - it will have negative excess reserves. In this situation, the bank must borrow reserves from the central bank at a penalty rate, $r_{p}$, so that its excess reserves are at least zero. (The value of $r_{p}$ includes both the explicit rate charged for borrowing reserves as well as any non-pecuniary stigma associated with discount window borrowing.) If the payment shock implies that a bank ends up with positive excess reserves, the central bank pays interest on those reserves, IOR. IOR is strictly less than $r_{p}$ and could be equal to zero.

If payment shocks are uniformly distributed around zero, then a bank's demand curve for reserves is described by Figure 1, above (see Ennis and Keister, 2008, for a formal derivation). The demand curve is the locus of indifference points for the bank. Specifically, a bank is indifferent between borrowing and lending a marginal unit of reserves at each combination of interest rate and reserve holdings along the demand curve.

\footnotetext{
${ }^{7}$ Some recent work has used other types of model such as search and bargaining or preferred habitat, in contrast to perfect competition in Poole (1968). See for example Afonso and Lagos (2015), Afonso, Armenter, and Lester (2019), Armenter and Lester (2017), Schulhofer-Wohl and Clouse (2018), Kim, Martin and Nosal (forthcoming), and Chen, Clouse, Ihrig, and Klee (2016). Still, in some of these works, demand for reserves originates from required reserves and timing of shocks that are broadly consistent with Poole (1968).
} 
After the payment shock, the marginal value of reserves to the bank is equal to the penalty rate $r_{p}$ if the bank has negative excess reserves, and is equal to IOR if the bank has positive excess reserves. Before the payment shock, the bank's willingness to pay for reserves is the expected marginal value. Therefore, if a bank's excess reserves are so low that it always ends with negative excess reserves after the payments shock, the bank is willing to borrow reserves in the interbank market at rates up to the penalty rate, $r_{p}$. A bank with higher excess reserves has a positive probability that its excess reserves are positive following the payment shock, so its willingness to pay for an additional dollar of reserves is below $r_{p}$. Finally, if a bank's excess reserves are so high that it always holds positive excess reserves following any payment shock, then the bank is indifferent between borrowing and lending reserves at IOR. ${ }^{8}$ Hence, the bank's demand curve for reserves has a (weakly) negative slope and lies between IOR and $r_{p}$, as illustrated in Figure 1.

The equilibrium interbank rate is determined by equalizing aggregate demand and aggregate supply. ${ }^{9}$ The aggregate demand curve for reserves is simply the horizontal summation of the individual banks' demand curves; if banks are identical, the shape of the aggregate demand curve is identical to the individual demand curve. The central bank supplies an exogenous amount of reserves to the banking sector. A vertical line in the interest rate-reserve space represents the aggregate supply of reserves. Figure 2 illustrates two different aggregate supply curves, $S_{1}$ and $S_{2}$. If the aggregate supply of reserves is $S_{1}$, then the interbank rate, $r b_{1}$, exceeds IOR; if the aggregate supply is $S_{2}$, then the interbank rate, $r b_{2}$, equals IOR.

\footnotetext{
${ }^{8} \mathrm{We}$ abstract from risk premia for simplicity.

${ }^{9}$ In addition, the equilibrium interbank rate equalizes the aggregate demand for loans in the interbank market with the aggregate supply of loans in that market. This is the case because a bank's demand for interbank loans equals the difference between its reserves when the market opens and the quantity of reserves it demands; thus, the aggregate demand for interbank loans equals the aggregate supply of interbank loans if and only if the aggregate demand for reserves equals the aggregate supply of reserves.
} 


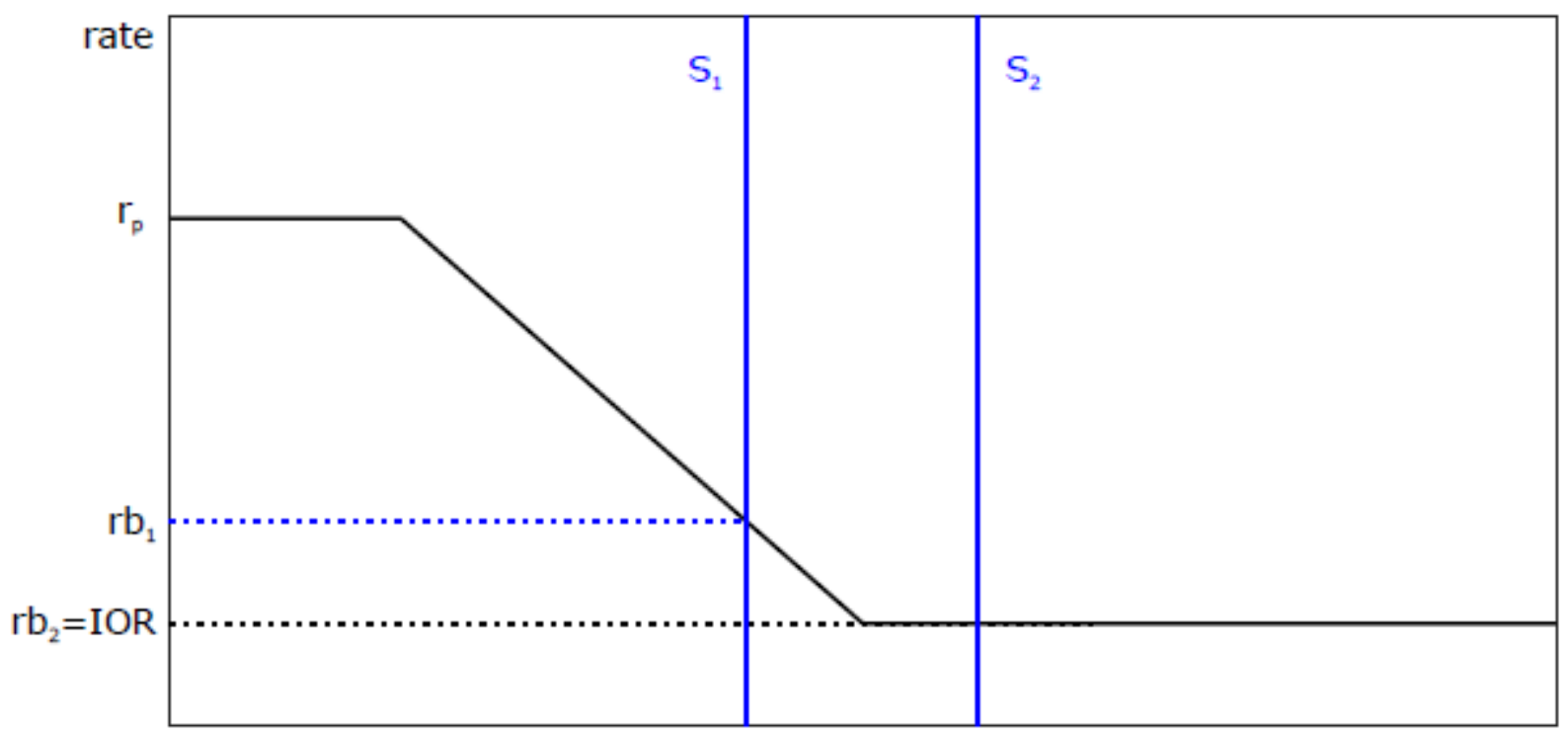

reserve

Figure 2: Equilibrium in the Poole Model.

In the standard model, equilibrium in the interbank market is characterized by all banks having the same marginal value of excess reserves when the interbank market closes, independent of the initial distribution of reserves across banks. This common marginal value of excess reserves is the interbank rate. If the interbank rate exceeds IOR, then assuming that banks have identical preferences, all banks must have the same amount of excess reserves when the interbank market closes. Hence, if the aggregate supply of reserves is on the steep part of the demand curve, banks holding more than the average amount of excess reserves before the market opens lend in the interbank market and those holding less than the average amount borrow in the interbank market. However, if the interbank rate equals IOR, all we can say is that all banks will be on the flat part of the individual demand curve; there would be no incentive for borrowing or lending even if some banks were further to the right on the flat part of the curve than others.

Finally, the interbank market can be replaced with a more general funding market with non-bank lenders, and the demand curve for reserves in the standard model remains the same whether trading occurs in an interbank market or in some other funding market. ${ }^{10}$

\subsection{Post-crisis developments}

In this subsection, we first discuss the impact of liquidity regulation on the demand for reserves. Then we consider how other post-crisis regulatory changes have increased the regulatory costs of expanding a bank's balance sheet and trading in money markets.

\footnotetext{
${ }^{10}$ See, for example Kim, Martin and Nosal (forthcoming).
} 


\subsubsection{Post-crisis changes: liquidity regulation}

In the standard model, a bank's sole reason for demanding reserves is to satisfy reserve requirements. Banks' liquidity risk management in the context of post-crisis regulations results in a new and independent source for demand for reserves by banks. For example, the liquidity coverage ratio (LCR) requires banks to hold sufficient HQLA to meet net cash outflows over a thirty-day stress period. HQLA include government securities and central bank reserves, as well as some other safe and liquid assets. The LCR regulation implies that, compared to the pre-crisis period, banks' demands for the sum of government securities and reserves increase. However, as we discuss below, banks have a choice about how to allocate their HQLA between government securities and reserves; the LCR does not contain specific requirements about reserves per se. In addition, banks' internal liquidity stress tests play an important role in the demand for reserves.

Figure 3 illustrates the effect that liquidity risk management and regulation have on the demand for reserves. Starting from the standard model's demand curve, the liquidity regulation shifts out the demand curve by the additional amount of reserves that banks choose to hold.

In Figure 3, the outer demand curve labeled "maximum demand" represents the demand curve for reserves if banks choose to satisfy their LCR requirements with reserves only. Banks could choose a different mix of reserves and other types of HQLA to satisfy the LCR requirements: For example, a bank may prefer to hold more reserves than government securities if the yields on government securities are relatively low or if the bank thinks that it could be challenging to quickly convert government securities to cash in the face of outflows. And, of course, a number of other considerations may be important.

Since banks' exact preferences are hard to determine from a central bank's perspective, there is uncertainty in the amount of the increase in reserve demand due to liquidity regulations and banks' liquidity risk management. The inner demand curve represents the minimum demand curve for reserves, where banks meet their LCR requirements mostly with other types of HQLA such as government and mortgage-backed securities rather than reserves. Importantly, these curves illustrate the perspective of the central bank or of a market observer, not that of an individual bank. Any individual bank still has a single demand curve, located somewhere between the inner and outer curves, but its location depends on a host of considerations that are completely known only to the bank itself.

If the aggregate supply of reserves is given by $S_{1}$ in Figure 3, then the interbank rate equals IOR with the minimum demand curve but exceeds IOR with the maximum demand curve. If, however, the aggregate supply of reserves is instead very large as given by $S_{2}$, then the interbank rate is equal to IOR for both the minimum and the maximum demand curves. Figure 3 reinforces the idea that the lower kink of the demand curve is an endogenous object and by extension so is the idea of reserves being "scarce" or "abundant." Uncertainty about the location of the kink matters more for market interest rates at intermediate levels of reserves. At sufficiently low aggregate levels of reserves, the market rate will be $r_{p}$ regardless of which demand curve is in effect; at sufficiently high aggregate levels of reserves, the market rate will be IOR regardless of which demand curve is in effect. But at intermediate levels of reserves, the gap between the 
possible demand curves is larger and so is the uncertainty about the market interest rate associated with a given aggregate supply of reserves.

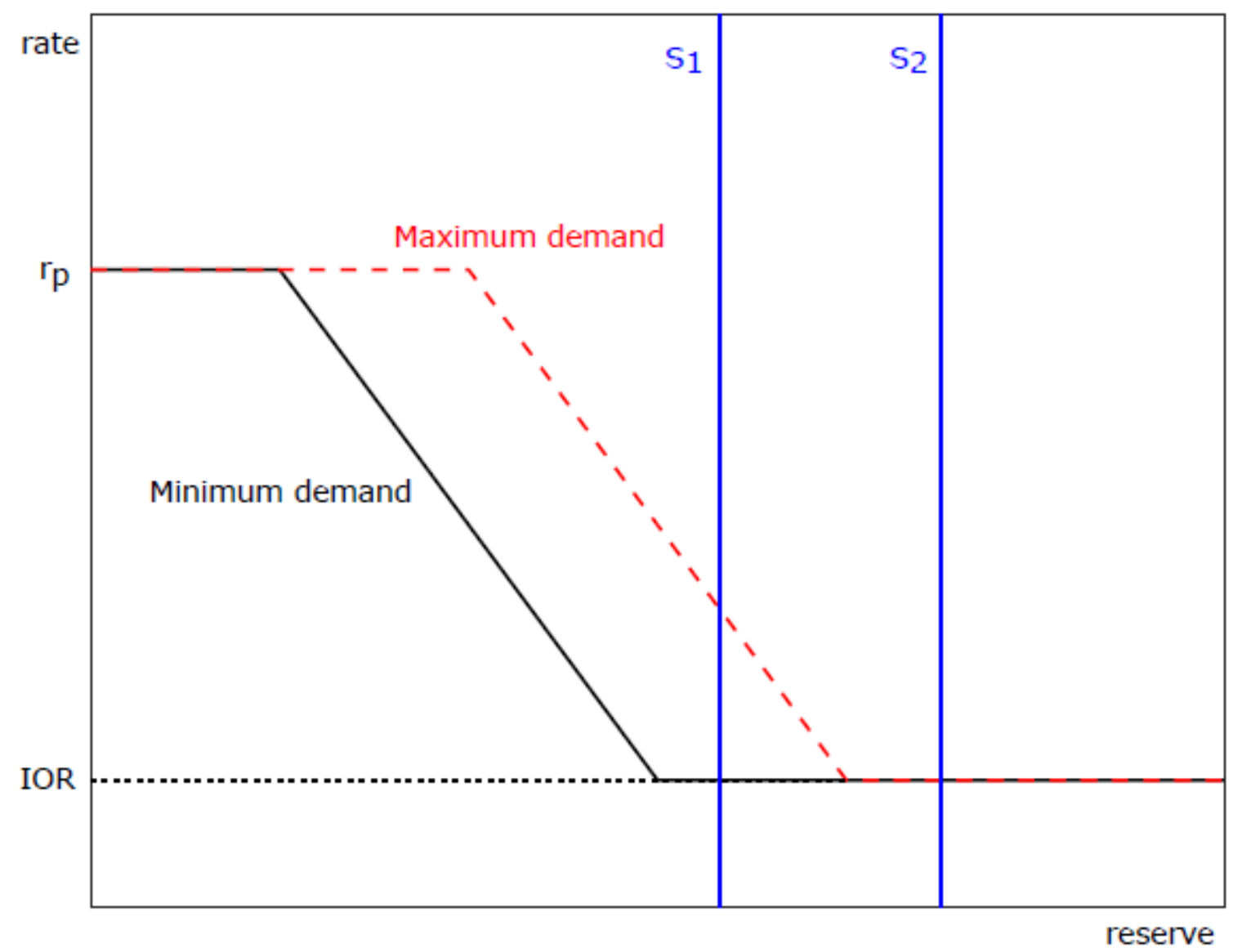

Figure 3: Effect of Demand Uncertainty.

\subsubsection{Post-crisis changes: balance sheet and trading costs}

Other post-crisis regulatory changes increased the regulatory costs of expanding a bank's balance sheet or otherwise trading in money markets. One example is stricter rules on the leverage ratio. Another is that, in the United States, a bank's Federal Deposit Insurance Corporation (FDIC) fee is currently based on the size of its balance sheet, while pre-crisis the fee was based on the size of the bank's deposit liabilities.

In the setup of the standard model, if a bank lends in the interbank market, its reserve holdings fall but its balance sheet stays the same since the interbank loan replaces reserves as an asset on its balance sheet. If a bank borrows in the interbank market, its reserve holdings increase and its 
balance sheet expands. ${ }^{11}$ On net, the aggregate balance sheet of the two banks expands. Thus, balance sheet costs act as an implicit tax on interbank trading and decrease trade volume in the interbank market.

Other post-crisis changes that are not technically balance sheet costs can also have the effect of increasing banks' perceived cost of trading. For example, an enhanced focus on risk management may lead a bank to limit its positions with any one counterparty. Counterparty limits could then prevent the bank from lending to some potential borrowers who value reserves more highly.

Suppose for simplicity that the marginal implicit cost of interbank trading, $c$, is constant. For example, trading costs would take this form if a bank's regulation fee increases by $c$ when its balance sheet increases by a dollar. This sort of regulation drives a wedge between a (potential) borrowing bank's demand curve and a (potential) lending bank's demand curve for reserves, where the size of the wedge equals $c$ (for details, see Kim, Martin and Nosal, forthcoming). Figure 4 illustrates demand curves for borrowing and lending banks. When $c=0$, the two curves coincide. (For nonlinear trading costs, $c$ can be interpreted as the marginal cost of an additional dollar of trading, and the results described here apply locally, but the two demand curves would no longer be parallel.)

${ }^{11}$ To be precise, the balance sheet expands in expectation. If the payment shock turns out to be sufficiently negative, the borrowed reserves will decrease discount window borrowing one-for-one, thus not expanding the balance sheet. 

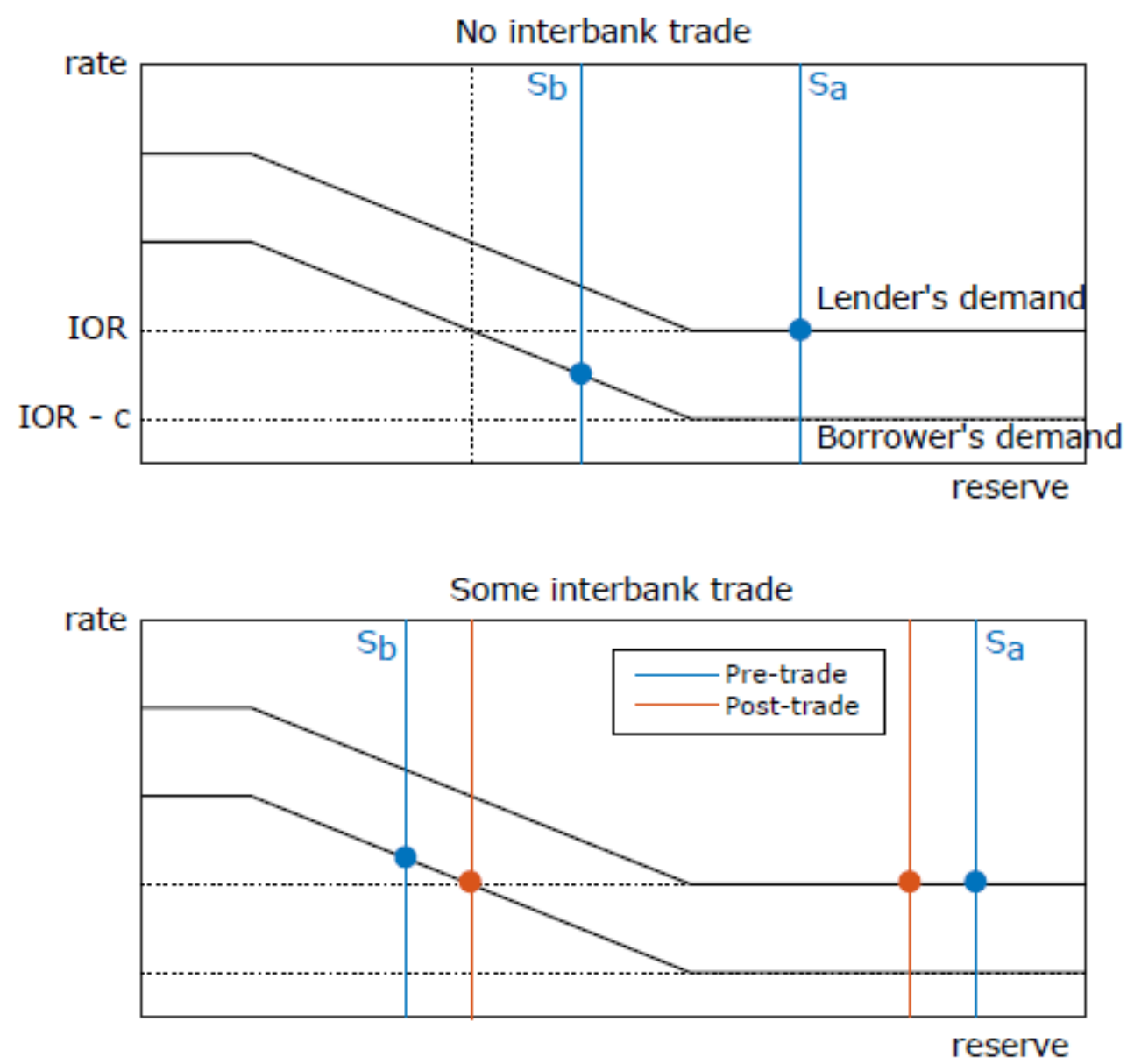

Figure 4: Balance Sheet Cost Wedge.

Suppose that the demand curves in Figure 4 are for two banks, where $S_{a}$ represents the excess reserves initially held by bank $a$ and $S_{b}$ represents the excess reserves initially held by bank $b$. Since $S_{a}>S_{b}$, bank $a$ is a potential lender and bank $b$ is a potential borrower in the interbank market. Therefore, the upper demand curve is associated with bank $a$ and the lower demand curve is associated with bank $b$.

A necessary condition for any interbank trade is that the potential borrower (bank $b$ ) must be willing to pay a higher rate than the reservation rate of the potential lender (bank $a$ ). In other words, the interest rate associated with bank $b$ 's demand curve evaluated at $S_{b}$ must exceed the interest rate associated with bank $a$ 's demand curve evaluated at $S_{a}$; otherwise there will be no interbank trade. The top panel on Figure 4 illustrates a situation where there is no trade in the interbank market. If, instead, $S_{b}$ were to the left of the vertical line marking where bank $b$ 's demand curve meets the lender's reservation rate (IOR in the figure), then banks $a$ and $b$ would trade in the interbank market, as shown by the bottom panel. Notice two things about the existence of interbank trades: (1) banks must have substantially different holdings of excess 
reserves before the market opens if there is to be any interbank trade; and (2) in contrast to the standard model, interbank trades do not completely equalize banks' excess reserve holdings, because in general the borrower's willingness to pay will fall below the lender's reservation rate before reserves are equalized. (In the bottom panel of figure 4, the gains from trade are exhausted when bank $b$ borrows enough reserves to increase its holdings from $S_{b}$ to the orange vertical line on the left, which decreases bank $a$ 's reserves only slightly, to the orange vertical line on the right.)

Absent balance sheet costs, all banks exit the interbank market holding the same level of excess reserves, the aggregate demand curve is a scaled-up version of an individual bank's demand curve, and the initial distribution of individual banks' excess reserve holdings is irrelevant. With balance sheet costs, which introduce a cost of trading, the distribution of excess reserves before the interbank market opens is relevant for determining the volume of interbank trade and the interbank rate. A simple way to introduce heterogeneity of excess reserve holdings before the interbank market opens is to augment the timing of the standard model in the following way: (1) All banks start off with the same level of excess reserves by borrowing from non-bank lenders. (2) Banks are hit by a shock that reallocates reserves among them, leading to different excess reserve holdings. (3) The interbank market opens and trade occurs. And (4) the interbank market closes and banks are hit by the standard shock introduced by Poole (1968). ${ }^{12}$

When balance sheet costs are zero, the "step 1" reserve demand curve is given by the standard demand curve, which is illustrated in Figure 2. When marginal balance sheet costs exist, the reserve demand curve from step 1 will be different from the standard demand curve since interbank trades no longer equalize banks' excess reserves holdings. The "step 1" demand curve for reserves is now "smoothed out" and lower compared with the standard curve, as illustrated in Figure 5. It is important to emphasize that the "step 1" demand curve determines the banks' funding or borrowing rate from non-bank lenders. Treating this funding rate as the policy rate is appropriate if interbank trading volumes are relatively small, which is currently the case in the United States.

The reserve demand curve lies below the standard demand curve because of the introduction of marginal balance sheet costs. It is "smoothed out" because even when the level of aggregate reserves exceeds the kink in the standard model's aggregate demand curve, reserves may not be "abundant": There is still a chance that a bank may experience a negative reallocation shock (in step 2 of the augmented timing) that reduces its excess reserves below the kink on its individual demand curve if the supply of reserves is sufficiently close to the kink of the aggregate demand curve. Since marginal balance sheet costs prevent interbank trades from completely offsetting this shock, banks will be willing to pay more to borrow reserves beforehand (in step 1 of the augmented timing). This willingness to pay gradually decreases as reserves increase, all the way down to zero, which has the effect of "smoothing out" the kink. Thus, our model can be interpreted as having three regions: one where reserves are scarce and the demand curve is steep, one where reserves are abundant and the demand curve is flat, and an intermediate region where

\footnotetext{
${ }^{12}$ See Kim, Martin and Nosal (forthcoming) for details and implications.
} 
the demand curve has a gentle slope - which one might refer to as "ample" reserves. As noted above, our use of these labels is not intended to reflect any views other than our own.

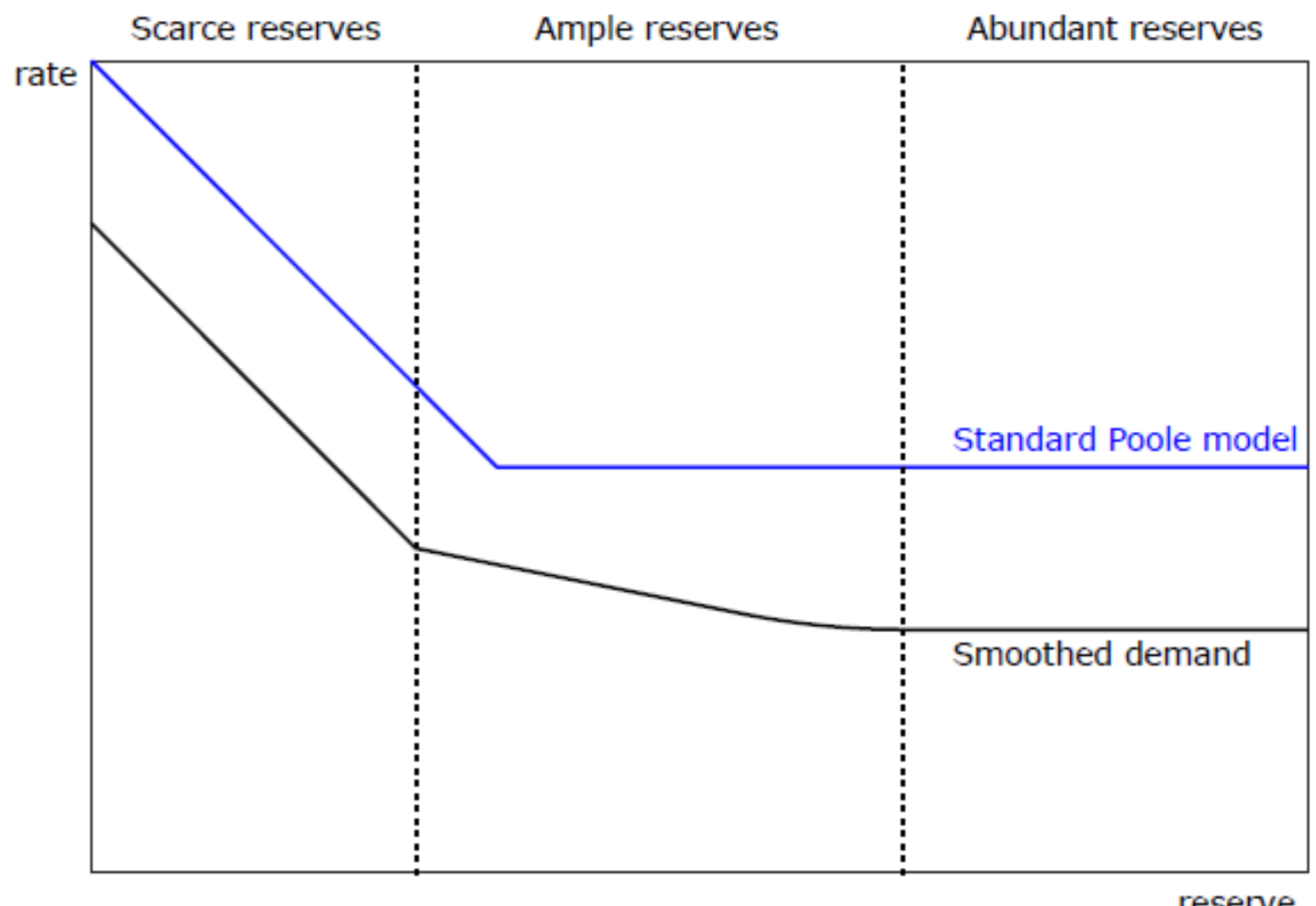

Figure 5: Smoothed Out Reserve Demand.

A smoothed kink in the demand function also arises in models that incorporate search and bargaining frictions to capture the over-the-counter nature of interbank markets. ${ }^{13}$ Search-based models bring in the idea that interbank trade might not occur, even if there are borrowers and lenders willing to trade, because there is a chance that a bank cannot find a counterparty to trade with. Banks take this risk into account when they negotiate transaction terms, ultimately influencing the rates banks are willing to pay for reserves.

\section{Post-Crisis Changes in Reserve Supply}

So far, we have focused on reserve demand and treated reserve supply as being entirely under the control of the central bank. However, in practice, a central bank must consider shocks, known as

\footnotetext{
${ }^{13}$ Ashcraft and Duffie (2007) is the first to emphasize the decentralized nature of the fed funds market. See Afonso and Lagos (2015), Afonso, Armenter, and Lester (2019), Armenter and Lester (2017), Bech and Klee (2011), Bech and Monnet (2016), Berentsen and Monnet (2008), Schulhofer-Wohl and Clouse (2018), Williamson (2015) and references therein for models of search and bargaining in interbank markets.
} 
autonomous factors, that move reserve supply. This section describes how day-to-day changes in supply have become much bigger in the United States in recent years. As we will see in the next section, this development can make implementation with scarce reserves more difficult. Even though we use the United States as our main example, similar changes have occurred elsewhere.

In the absence of open market operations by the Federal Reserve, the supply of reserves available to banks changes daily, as reserves are withdrawn as physical currency (bills and coins) and moved to and from accounts held by non-bank entities, such as the Treasury General Account (TGA) or accounts of government-sponsored enterprises and financial market utilities.

Generally, exogenous day-to-day changes in the supply of reserves are mostly predictable, but the volatility of these changes has increased significantly.

Figure 6 shows that the week-to-week volatility in selected autonomous factors increased substantially, particularly physical currency and reserve accounts held by non-bank entities. A dollar increase in an autonomous factor causes a dollar decrease in reserve supply available to banks, and vice versa. As a result, the volatility of reserve supply has increased substantially.

In principle, the Federal Reserve can affect the volatility of autonomous factors, but only to a limited extent. ${ }^{14}$ In addition, restricting this volatility may not always be desirable. For example, since 2015 , the Treasury has attempted to maintain a five-day liquidity buffer in its account, to limit the risk that it might not be able to access the market, for example due to an operational outage such as a cyber-attack. ${ }^{15}$ While this buffer contributes to a larger autonomous factor, it might not be possible or desirable to return to the pre-crisis situation. In addition to the buffer's resiliency benefit to Treasury, banks may be less interested than in the pre-crisis period in taking large and volatile cash balances from Treasury given how this volatility might affect their liquidity risk management.

\footnotetext{
${ }^{14}$ It would be difficult to regulate withdrawal and deposit of physical currency. The Fed could set up rules on the use of accounts held by non-banks, but it would be difficult to force entities holding these accounts to reduce volatility in their account balances substantially without regard to their operational needs; indeed, free withdrawal and deposit is a primary advantage of holding cash or reserves.

${ }^{15}$ The Treasury's May 6, 2015, quarterly refunding statement notes: "Based on our review, the TBAC's recommendations, and an assessment of emerging threats, such as potential cyber-attacks, Treasury believes it is prudent to change its cash management policy starting this month. To help protect against a potential interruption in market access, Treasury will hold a level of cash generally sufficient to cover one week of outflows in the Treasury General Account, subject to a minimum balance of roughly $\$ 150$ billion.”
} 

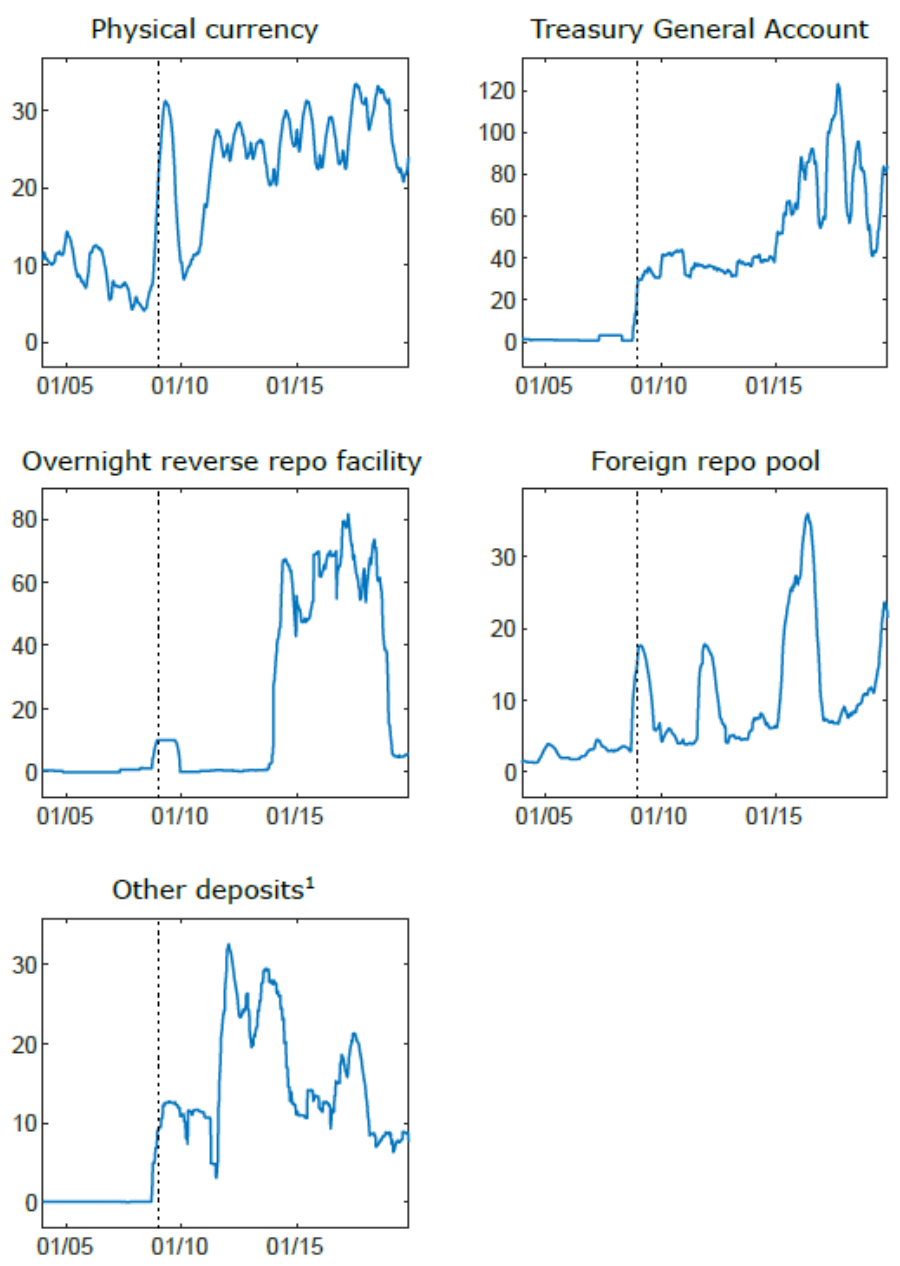

1. Other deposits are held by various official and private institutions. 2. The vertical lines mark the beginning of 2009, a few months after the first series of large-scale reserve injections.

3. All numbers are in billions USD.

Figure 6: Volatility in Selected Autonomous Factors in the United States. ${ }^{16}$

As shown in Figure 7, the overall week-to-week volatility in reserve supply - measured as the standard deviation of the first difference - stood at about $\$ 120$ billion in mid-September 2019, right before the Federal Reserve began operations to increase reserve supply; note that volatility for several years after the crisis was driven by asset purchases, and accurately reflects exogenous reserve supply changes only for the period after asset purchases ended and before reserveinjecting operations began. ${ }^{17}$

\footnotetext{
${ }^{16}$ Time period covered is from 2003 to present. Volatility is calculated using publicly released weekly snapshots for 52-week trailing windows, as the standard deviation of the first difference.

${ }^{17}$ After large-scale reserve injections following the crisis, the Federal Reserve no longer conducted daily open market operations to fine-tune reserve supply. However, it did so pre-crisis. Therefore, pre-crisis figures do not reflect volatility in exogenous reserve supply. Similarly, current reserve-injecting operations tend to offset reductions in reserve supply.
} 


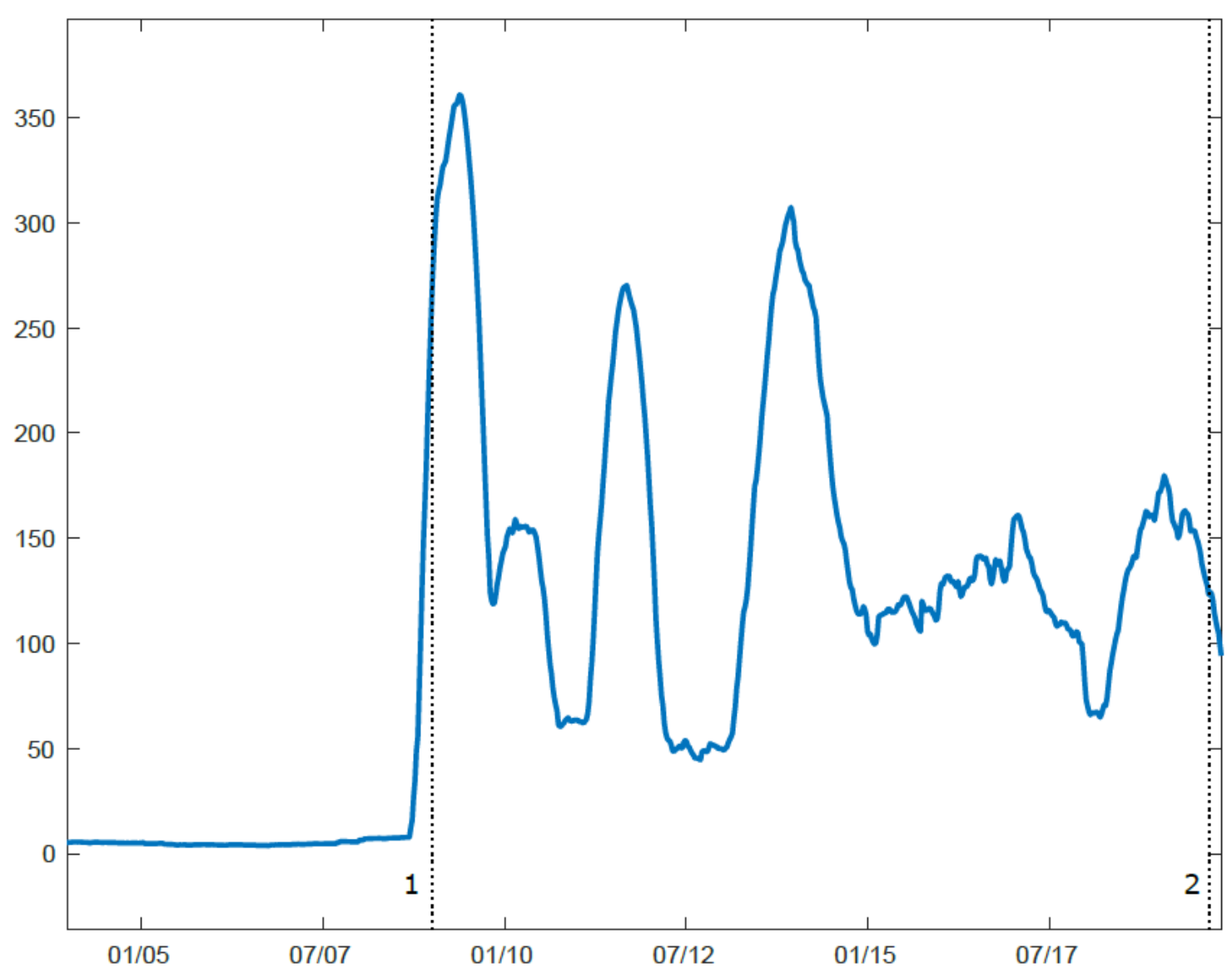

1. The vertical line on the left marks the beginning of 2009, a few months after the the first series of large-scale reserve injections.

2. The vertical line on the right marks the beginning of reserve-injecting operations (September 17, 2019).

3. All numbers are in billions of USD.

Figure 7: Volatility in Reserve Supply in the United States. ${ }^{18}$

\section{A Simple Model of Monetary Policy Implementation}

We now synthesize the above discussions of reserve demand and supply into a simple but general framework that describes how a central bank can implement monetary policy - i.e., employ its tools to control an overnight market interest rate.

In the model, we assume that the overnight market interest rate is a function of the interest rate on reserves, the aggregate supply of reserves, and random shocks to demand, based on the reserve demand curve developed in the previous section. The central bank chooses the interest rate on reserves and a targeted level of aggregate reserves that it seeks to supply. However, the

${ }^{18}$ The time period covered is from 2003 to present. Volatility is calculated using publicly released weekly snapshots for 52-week trailing windows. Volatility is calculated as the standard deviation of the first difference. 
actual aggregate supply of reserves is subject to shocks such as tax payments that can add or remove reserves.

In consequence, after choosing an interest rate on reserves and a target aggregate level of reserves, the central bank still faces some uncertainty about the overnight market interest rate that will result. We show that this uncertainty is smaller at higher levels of aggregate reserves, and (in our simple model) the uncertainty is eliminated at sufficiently high levels of reserves. If the central bank were concerned only with eliminating uncertainty about the overnight market rate, these results would motivate supplying a high level of reserves.

However, the central bank may perceive costs to a high level of reserves and seek to operate at a lower level. If so, it faces tradeoffs between the costs of supplying more reserves and the costs of interest rate volatility, as well as the costs of conducting open market operations to offset reserve supply shocks. We show that the optimal balance among these tradeoffs depends on how large the gently sloped region of the reserve demand curve is. If this region is large, the central bank can operate within it, economize on reserves, and yet not experience much rate volatility. But if this region is small, the central bank will experience a greater degree of rate volatility when attempting to operate close to the region where reserves become scarce.

The remainder of this section provides technical details on the model, discusses potential costs and benefits of different levels of reserve supply, and uses the model to formally analyze the tradeoffs between costs (or benefits) of reserve supply, rate volatility, and frequency of operations.

\subsection{Model}

We assume that the central bank's policy rate (for example, the federal funds rate in the United States) is a market interest rate that is function of aggregate reserve supply, a reserve demand shock ( $\delta D E M A N D)$ and IOR: ${ }^{19}$

$$
\text { rate (reserve supply, } \delta D E M A N D, I O R) \text {. }
$$

This function specifies the equilibrium rate. Since reserve supply is an exogenous quantity, the function traces out the aggregate demand curve for reserves as reserve supply is varied. We assume that an increase or decrease in IOR shifts the rate function up or down one-for-one, since a basis point increase in both IOR and banks' funding rate does not change the net cost of obtaining reserves. ${ }^{20}$

\footnotetext{
${ }^{19}$ In principle, other administered rates such as the penalty rate in the baseline model affect the equilibrium rate. Implicitly, we assume that the spreads between such rates and IOR are kept constant.

${ }^{20}$ This assumption is consistent with various models if we assume that the penalty rate and rates on other facilities (such as the overnight reverse repo program by the Federal Reserve) increase or decrease, one-for-one, with changes in the IOR. This assumption did not hold when the Federal Reserve made technical adjustments, changing the spread between the IOR and the overnight reverse repo offer rate. However, the federal funds rate still moved one-to-one with the IOR, as shown in Figure 17.
} 
The demand shock shifts the demand curve to the left or right when the shock is negative or positive, respectively. In contrast to the pre-crisis period, when banks' aggregate demand for reserves was always close to required reserves and, thus, easier to forecast, the uncertainty in banks' demand for reserves increased substantially after the crisis. As we discussed above, this uncertainty about the shape of and shifts in the demand curve for reserves is due, in part, to changes in supervision, regulation, and banks' risk management practices.

Under these assumptions, the rate function can be written as the sum of IOR and a spread that depends on reserve supply and the demand shock:

$$
\text { rate }=I O R+\operatorname{spread}(\text { reserve supply }-\delta D E M A N D) .
$$

We note that the function spread can take negative values, especially with significant balance sheet costs. Furthermore, we assume that the function spread is continuous, monotonically decreasing and convex. In the absence of changes in market structure linked to changes in reserve supply, the assumption of monotonic decrease is generally accepted. Convexity is consistent with the rate being insensitive to changes in reserve supply with an abundant supply of reserves and being sensitive with a scarce supply. ${ }^{21}$

Reserve supply is also subject to shocks due to changes in autonomous factors, such as withdrawal and deposit of physical bills and coins and movements of reserves between the banking system and special accounts outside the banking system. In the absence of open market operations to offset such shocks, we can write

$$
\text { reserve supply }=\text { TARGET }+\delta S U P P L Y,
$$

where TARGET is the target level of reserve supply that the central bank chooses and $\delta S U P P L Y$ is the shock to reserve supply.

We interpret this framework as describing what happens on a single day, and abstract from the accumulation of shocks over multiple days, trends in reserve demand, and so on.

\subsection{Benefits and Costs of Large and Small Reserve Supply}

The equations above determine the policy rate given a choice of reserve supply by the central bank and the realization of exogenous shocks. To think about optimal policy in the context of this model, we need to specify the central bank's objective function. Commentators have discussed a number of costs and benefits associated with different levels of reserve supply that might form part of that function.

Potential costs associated with a regime of scarce reserves include: the effort that banks expend on trading reserves with each other late in the day as each bank tries to meet but not exceed its

\footnotetext{
${ }^{21}$ If market structure or trade patterns change as reserve supply changes, then convexity is no longer a reasonable assumption. For examples of such cases, see Afonso, Armenter, and Lester (2019) and Kim, Martin and Nosal (forthcoming).
} 
reserve requirement; the resulting interconnectedness between banks, which can be detrimental during periods of stress; inefficiencies in the payments system and increased operational risks as banks may delay outgoing payments to reduce the risk of facing a shortfall of reserves; ${ }^{22}$ and the need to conduct frequent, often daily, open market operations to fine-tune the supply of reserves to keep the policy rate at a given target. ${ }^{23}$ In addition, as discussed later, a large supply of reserves may enhance the stability of financial markets.

However, a smaller supply of reserves also has potential benefits. Interest payments to banks will be smaller and, thus, any political economy concerns associated with these interest payments will be lessened. (Note, however, that the central bank's net income, the difference between income and expenses, does not necessarily increase as reserves decrease, because the central bank holds a dollar of assets for each dollar in liabilities.) Further, banks' need to trade reserves when reserves are scarce promotes the existence of active interbank markets that can help redistribute reserves and insure against unexpected shocks.

The costs and benefits of different reserve levels must be weighed against the effectiveness of interest rate control. Rather than trying to capture each cost or benefit explicitly, we assume that the central bank cares about control of the policy rate, taking into account the implications for the frequency of operations and the size of its balance sheet. As the supply of reserves decreases, the frequency of operations increases, and even with more frequent operations, the variability of the policy rate increases because operations cannot offset all shocks. Thus, the central bank faces a tradeoff between rate control and the size of its balance sheet, as well as the frequency of operations. In the U.S. context, we interpret these tradeoffs as capturing, on the one hand, the desire to remain in a regime where active adjustment in reserve supply is not needed to implement policy and, on the other hand, the desire to operate with a balance sheet that is no larger than necessary for efficient and effective policy implementation.

\subsection{Implementation in the Post-Crisis Environment}

Both the easier-to-forecast supply shocks and harder-to-forecast demand shocks increased in magnitude since the financial crisis. Combined with the increase in balance sheet costs, these changes would create challenges for the pre-crisis implementation regime based on scarce reserves, as we now discuss.

For a moment, we set aside uncertainty in reserve demand and focus only on supply shocks. Under a scarce-reserves regime, open market operations are conducted daily to offset exogenous reserve supply shocks. This is necessary because the policy rate is very sensitive to changes in the supply of reserves when reserves are scarce.

Since the magnitude of reserve supply shocks has increased relative to the pre-crisis regime, controlling the policy rate in a scarce-reserves regime would require larger offsetting operations. At the same time, due to higher balance sheet costs and other regulatory changes that affect the

${ }^{22}$ See Bech, Martin, and McAndrews (2012) and Garratt, Martin, and McAndrews (2014), for example.

${ }^{23}$ See Logan (2017) and FOMC (2016). 
implicit cost of trading, financial institutions could be less willing to engage in open market operations, more so if the operations are large. Therefore, it could be difficult at times for a central bank facing volatile autonomous factors to conduct open market operations in the desired size. Still, if demand for reserves or funding is high enough, there might be little difficulty in conducting operations, as demonstrated for example by the Federal Reserve's repo operations in fall 2019.

Adding in demand uncertainty, such as demand shocks that are challenging to forecast, the scarce-reserves regime could become even more difficult to implement. Indeed, if demand shocks cannot be forecasted precisely, they cannot be offset perfectly. As a result, the policy rate would fluctuate with the realization of demand shocks unless additional tools were used to control rate movements. Such fluctuations already occurred to a small degree pre-crisis, despite the relative simplicity of forecasting and responding to reserve supply and demand at that time.

With abundant reserves, rate control is generally not an issue. If reserves are abundant enough, the policy rate would not be expected to move for any realization of supply and demand shocks. In particular, this remains true even without any open market operations by the central bank. This was generally the case for the United States during the post-crisis period until September 2019. Between December 2015 and mid-September 2019, the effective federal funds rate rarely changed from one day to the next, despite sizable autonomous factors, and even in the absence of operations by the Federal Reserve.

If reserves are already abundant, though, adding more reserves does not enhance monetary policy implementation. This is because policy rate volatility and the cost of open market operations are already zero and an increase in reserves cannot further reduce these costs. Over the range of reserve supply where these costs are zero, the central bank can choose its preferred level of reserves using another criterion; for example, it can simply choose the lower bound of the range.

Indeed, a central bank that has a preference for lower reserves, for a given level of policy rate volatility and a given cost of open market operations, will generally choose a level of supply below the lower bound of the range of abundant reserves (see Figure 5). Therefore, for a central bank that finds a scarce-reserves regime inefficient due to rate variability and frequency of operations but has a preference for lower reserves, the optimal choice of reserve supply is somewhere between scarcity and abundance: what we refer to as ample. ${ }^{24}$ To discuss how ample reserves need to be, we characterize rate volatility and frequency of operations as a function of reserve supply.

\subsubsection{Implementation under a Maximum Spread Variability Constraint}

In this section, we present a simple characterization of operational costs. The central bank chooses a target level of reserves supply, TARGET, to keep the variation in the spread between

\footnotetext{
${ }^{24}$ The language of "between scarcity and abundance" is approximate. For example, it is possible that a target level of reserves is in the abundant range but demand and supply shocks are large enough to sometimes move reserve supply outside the abundant range. In that case, if the target reserve supply is close to the lower limit of the abundant range, the costs associated with rate volatility and open market operations may not be zero.
} 
the policy rate and IOR below some tolerance level, TOL. In this framework, the central bank can satisfy its rate control objective without any open market operation if

$$
\begin{aligned}
\operatorname{spread}(T A R G E T+\min (\delta S U P P L Y)-\max (\delta D E M A N D)) \\
-\operatorname{spread}(T A R G E T+\max (\delta S U P P L Y)-\min (\delta D E M A N D)) \leq T O L .
\end{aligned}
$$

For simplicity, we assume that supply and demand shocks are independent. Figure 8 illustrates the case graphically. min and $\max$ are the minimum and maximum of supply and demand shocks. The min values will be negative and the $\max$ values will be positive for both shocks. ${ }^{25} \mathrm{With}$ a convex spread function, the rate control objective is satisfied only if TARGET is larger than a certain level. ${ }^{26}$

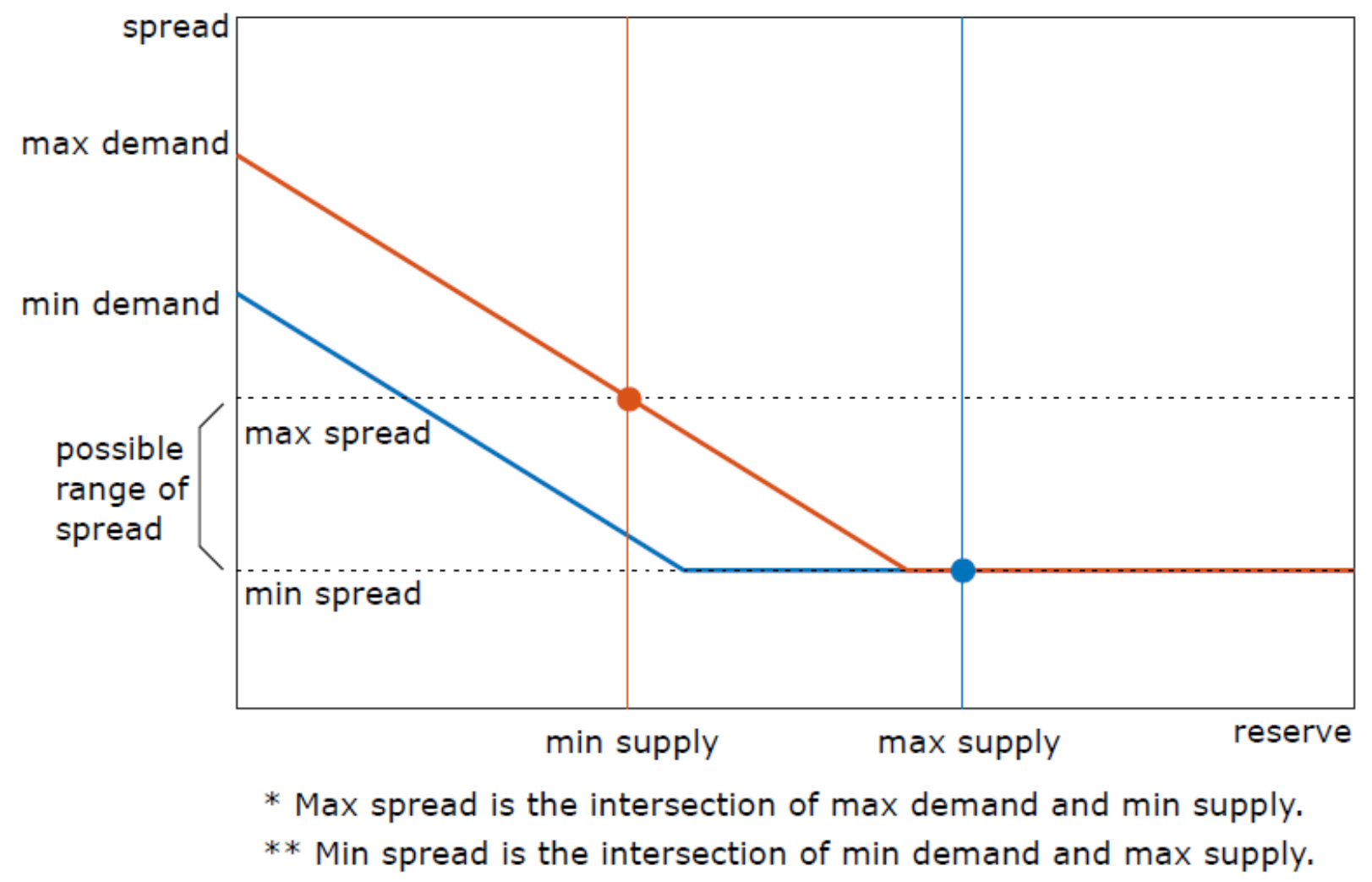

Figure 8: Possible Range of Spreads.

At the other extreme, it may not be possible to achieve the rate control objective even if supply shocks are completely offset by operations because demand shocks are, by nature, unknown and cannot be offset preemptively. (If any supply shocks cannot be perfectly predicted, the same problem will arise.) This will happen if

\footnotetext{
${ }^{25}$ This is a normalization. For demand shocks, we can redefine spread. For supply shocks, we can take out "trend" by subtracting the mean or the median.

${ }^{26}$ Since spread is continuous, the relationship is also satisfied at that minimum reserve level. Generally we are not rigorous about such details given the purpose of this paper.
} 


$$
\operatorname{spread}(T A R G E T-\max (\delta D E M A N D))-\operatorname{spread}(T A R G E T-\min (\delta D E M A N D))>T O L .
$$

Given convexity of the spread function, this will happen only if TARGET is smaller than a certain level.

Figure 9 illustrates the two limit levels of reserves. There is an intuitive link between the three regions on the figure and what we call scarce, ample and abundant reserve supply. The region labeled "too much rate volatility" might be wider than the scarce-reserves region in Figure 5, as rate volatility could become unacceptably large even if reserves exceed the maximum value associated with scarce reserves. Similarly, the region labeled "no need for operations" might be wider than the abundant-reserve region in Figure 5. Indeed, with the gently increasing slope of aggregate reserve demand, rate volatility would be small for reserve supply just below abundant levels and, as a result, there might not be a need for open market operations.

The shaded region in Figure 9 is our region of interest. If a central bank wants to adopt a scarcereserves framework with no remedy for increased volatility in supply and uncertainty in demand, it might fall into the region we label "too much rate volatility." In contrast, if the supply of reserves were sufficiently large, a central bank would fall into the region labeled "no need for operations."

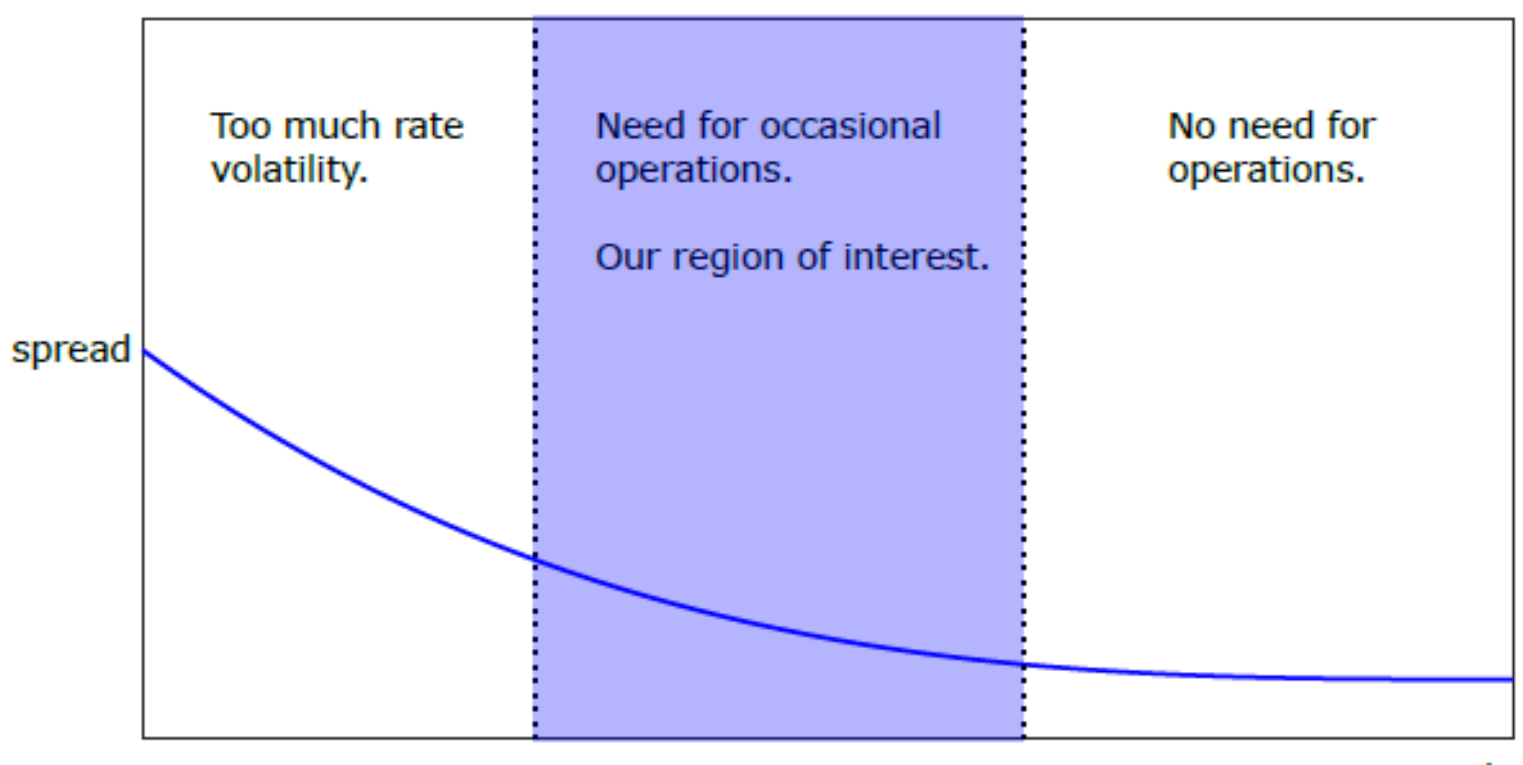

reserve supply

Figure 9: Illustration of the Three Regions.

Between these two limits, the policy rate can be controlled tightly but with infrequent open market operations. In practice, in an ample reserves regime, the central bank would likely choose to make infrequent outright purchases to offset the decline in reserves coming from growth of non-reserve liabilities, such as currency. Because our model is static, it does not consider growth of non-reserve liabilities. Nevertheless, infrequent operations in response to unusually large 
shocks have a similar flavor, in that both occasional operations in response to shocks and occasional outright purchases to offset growth of non-reserve liabilities are infrequent actions to offset declines in reserves.

We now consider where the central bank should set the supply of reserves within the moderately sloped region of the spread function, where adequate rate control can be achieved with occasional operations. In this region, the central bank is making marginal tradeoffs between balance sheet size and frequency of operations. Levels of reserves below this region are not optimal, independent of the tradeoff between balance sheet size and frequency of operations, because adequate rate control cannot be achieved, as illustrated in Figure 9.

Generally, an implementation regime can be represented by a target level of reserve supply as well as lower and upper intervention thresholds. For example, if a negative shock reduces the supply of reserves below the lower threshold, then the central bank would inject reserves to offset the shock. Conversely, if a positive supply shock increases the supply of reserves above the upper threshold, then the central bank would drain reserves. The tightness of intervention thresholds would determine the probability or frequency of operations over a certain horizon.

We simplify the problem even further by considering only reserve-injecting operations: The central bank conducts an offsetting operation only if a negative shock brings the supply of reserves below the lower threshold. This simplification is meant to capture the fact that trend growth in the central bank's non-reserve liabilities, such as currency, will naturally offset positive reserve supply shocks over time. Also, given the convexity of spread, the central bank would generally prefer more frequent reserve-injecting operations than reserve-draining ones to reduce the frequency of operations overall. ${ }^{27}$

We assume the cost of operations is proportional to the frequency or, equivalently, the probability of conducting operations. The central bank sets an intervention threshold, denoted THRES, that represents the farthest that reserve supply is allowed to fall below TARGET. Given a target level of reserve supply, the cost of operations is minimized while maintaining rate control by setting TARGET+THRES to correspond to the lowest possible supply of reserves consistent with the desired spread. Specifically, given our focus on only reserve-injecting operations, THRES is a negative number that solves the equation:

$$
\begin{aligned}
& \operatorname{spread}(T A R G E T+T H R E S-\max (\delta D E M A N D)) \\
& \quad-\operatorname{spread}(T A R G E T+\max (\delta S U P P L Y)-\min (\delta D E M A N D))=T O L .
\end{aligned}
$$

Therefore, inverting the spread function, we can write,

$$
\begin{gathered}
\text { THRES }=\operatorname{spread}^{-1}(\operatorname{spread}(T A R G E T+\max (\delta S U P P L Y)-\min (\delta D E M A N D))+T O L) \\
-T A R G E T+\max (\delta D E M A N D) .
\end{gathered}
$$

\footnotetext{
${ }^{27}$ If the supply shock is uniformly distributed, then as reserve supply declines, the threshold for reserve-injecting operations will increase all the way to zero before reserve-draining operations are ever used, even if we minimize intervention probability allowing both operations.
} 
Since spread is convex, a smaller target supply of reserves requires more frequent operations, as the policy rate becomes more sensitive to shocks.

This relationship is a key in determining the optimal level of reserve supply.

The absolute value of THRES is implicitly an increasing function of TARGET. So the optimal supply of reserves depends on how much the absolute value of THRES decreases as TARGET decreases. If the absolute value of THRES decreases only a little as TARGET decreases, it will generally make sense to reduce TARGET further as long as there is some preference for smaller reserve supply. For example, we could imagine a loss function to be minimized by the central bank:

$$
\operatorname{Prob}(\delta S U P P L Y \leq T H R E S)-(\text { constant }) \times T A R G E T .
$$

The rate at which the absolute value of THRES decreases as TARGET decreases is generally determined by the rate of change in the slope of spread. If TARGET decreases by $\$ 1$, both the minimum and the maximum reserve supply after shocks (plus supply shock and minus demand shock) decrease by $\$ 1$ as well. However, if the slope of spread is steeper at the minimum reserve supply than at the maximum, the range of the policy rate expands. Thus, the absolute value of THRES needs to decrease in response to suppress the upward movement in the policy rate and maintain rate control. Quantitatively,

$$
\frac{\partial T H R E S}{\partial T A R G E T}=\frac{\text { spread }^{\prime}(T A R G E T+\max (\delta S U P P L Y)-\min (\delta D E M A N D))}{\text { spread }^{\prime}(\text { TARGET }+ \text { THRES }-\max (\delta D E M A N D))}-1 .
$$

Figure 10 illustrates how the convexity of spread makes the central bank need a tighter intervention threshold for a smaller target supply of reserves. For ease of description, we assume that the demand shocks are zero. On the top panel, the slope of aggregate demand or spread is constant. The blue vertical lines show how the supply shocks and the intervention threshold determine the possible range of spread. The orange lines show the same for a smaller target level of reserves. In this case, since aggregate demand is linear (constant slope), there is no need to tighten the intervention threshold because the possible range of spread does not change with the target reserve supply.

In contrast, the bottom panel describes a case with a convex aggregate demand or spread. Without changing the intervention threshold, the range of interest rates or spread would be wider with a smaller target level of reserves. To implement an equal range of spread with a smaller target reserve supply, the central bank needs to tighten the threshold, as marked by the orange vertical and horizontal lines. 

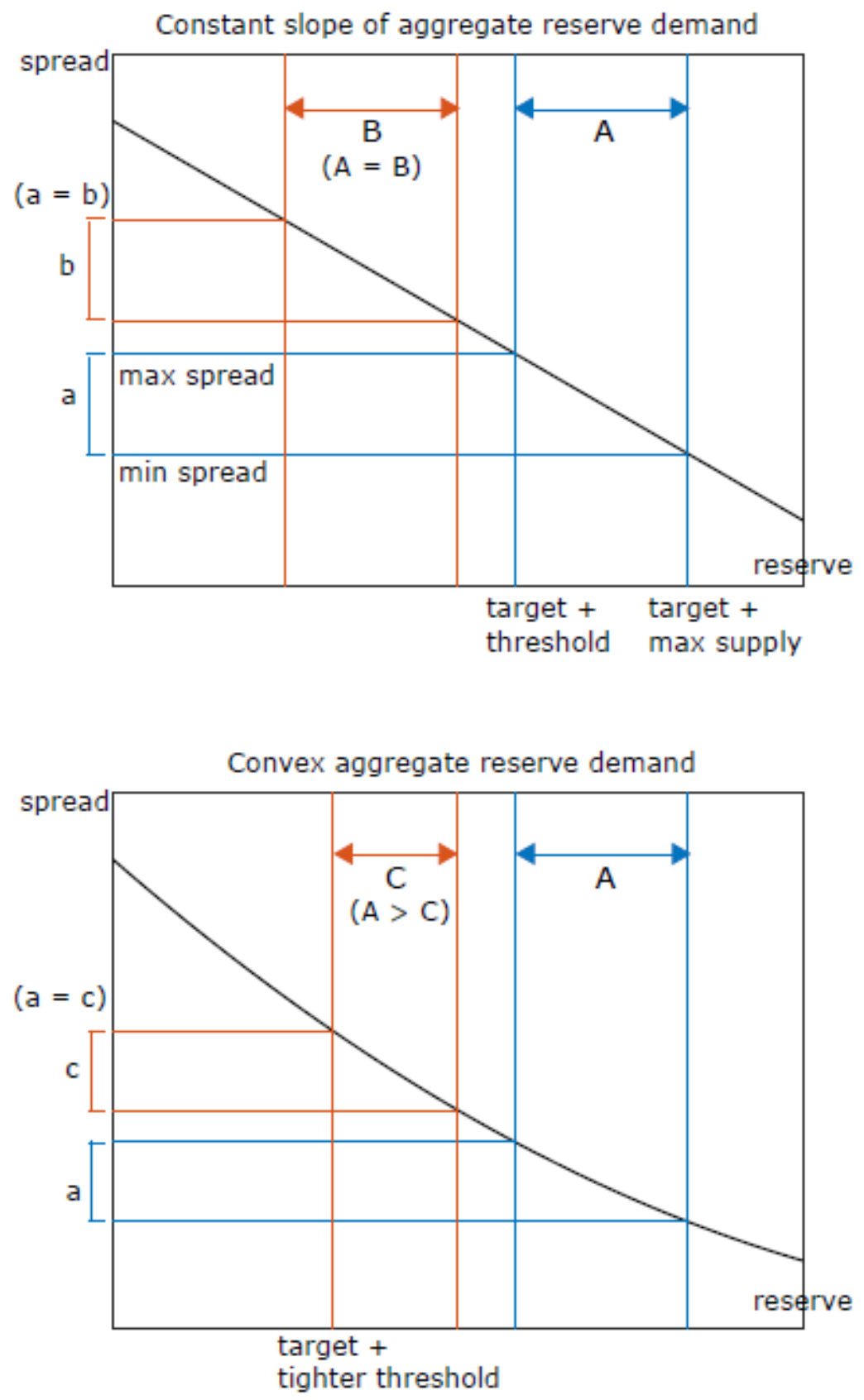

Figure 10: Effect of Convexity.

\subsection{A Simple Criterion for Optimal Reserve Supply in an Ample Reserves Regime}

In the previous section, we showed that in determining the optimal level of reserve supply within the region of occasional operations, the rate of change in the slope of the function spread matters. In this section, we develop this idea further: It is important to determine whether the reserve demand curve, or spread, has a sharp kink. By a sharp kink, we mean that the slope of spread transitions from near-zero to very steep over a narrow range of reserve supply. In such a 
case, the optimal reserve supply is essentially the location of the kink plus some buffer. In contrast, if the rate curve steepens gradually over a broad range of reserve supply, the optimal reserve supply becomes more sensitive to the central bank's preferences over operation frequency and reserve supply. In that case, the central bank might prefer to conduct both reserveinjecting and reserve-draining operations depending on the predicted sign of the supply shock. Importantly, in neither case would the central bank prefer to reduce reserves to a level so low that adequate rate control cannot be achieved.

A simple way to illustrate the effect of a sharp kink in the reserve demand is the standard model discussed earlier, which does not include balance sheet costs. The top panel on Figure 11 shows aggregate reserve demand. The rate curve in this model has a sharp distinction between scarce and abundant reserves: It has a completely flat region and a downward-sloping region with nothing in between.

For this example, we first assume that demand shocks are zero. There is a simple rule for operations: If a negative supply shock is large enough to decrease reserve supply below the value illustrated by the left vertical line in Figure 11, then the central bank needs to offset the shock. Therefore, the threshold for intervention increases one-to-one as the target reserve supply declines; this is the largest possible rate of increase, as can be seen from the expression for DTHRES/OTARGET.

If the supply shock is uniformly distributed over its support, then the increase in intervention probability associated with a decrease in the target reserve supply will be constant over the region between the two vertical lines in Figure 11. This leads to a simple rule for the optimal target reserve supply: If the marginal cost due to the increase in intervention frequency dominates the marginal benefit of a smaller reserve supply, the optimal point will be the upper limit of the region. As illustrated by Figure 11, intervention becomes necessary once the target reserve supply declines below the right vertical line. The necessary intervention rule is to simply keep the reserve supply above the left vertical line.

The middle panel on Figure 11 describes the intervention rule in more detail. The upper black diagonal line is a 45-degree line showing the location of the target (pre-shock) reserve supply. The minimum possible level of supply without any intervention is the 45-degree line shifted downward by the size of the minimum supply shock, as shown by the lower black line. As described earlier, the optimal intervention rule is to keep the reserve supply above the level indicated by the horizontal blue line. This means setting the intervention threshold at the level marked by the vertical distance between the blue horizontal line and the upper black 45-degree line.

Finally, the bottom panel shows the marginal benefit (blue) and cost (orange) of increasing the target reserve supply. The marginal benefit comes from reducing the expected frequency of operations. Since an increase in the target level of reserve supply lets the central bank decrease the intervention threshold by the same amount, the marginal benefit in terms of intervention probability is constant under the assumption of uniformly distributed shocks. However, once the target reserve supply is above the right vertical line, the marginal benefit is zero because 
intervention is not necessary. The marginal cost of having larger reserves is exogenous and shown for illustrative purposes, based on the example loss function seen previously:

$$
\operatorname{Prob}(\delta S U P P L Y \leq T H R E S)-(\text { constant }) \times T A R G E T .
$$

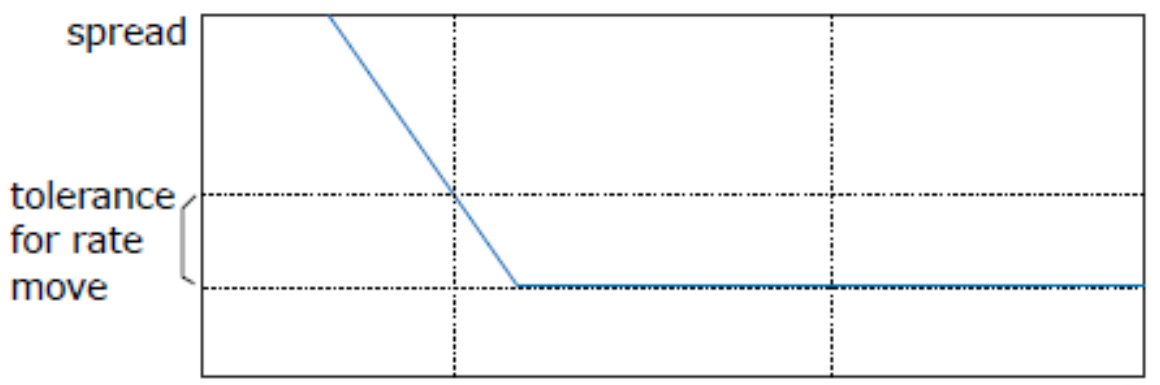

min. supply allowed by $\mathrm{CB}$

reserve supply
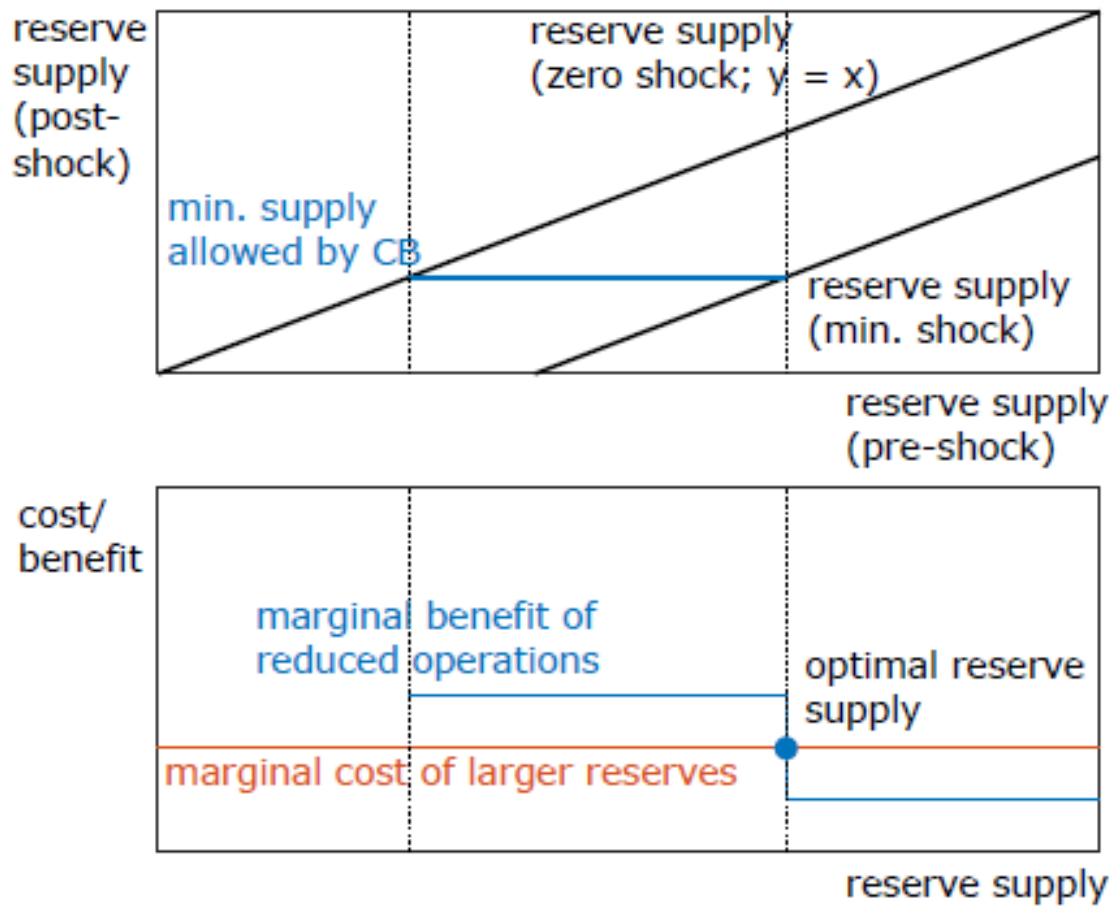

Figure 11: Implementation with a Sharp Kink.

With a less sharp change in the slope of spread, we expect a more gradual change in the operation threshold, as illustrated by Figure $12 .{ }^{28}$ In addition, the operation frequency increases at a lower and decreasing (in the example) rate as reserve supply decreases, thus making the optimal supply more sensitive to the exact form of reserve demand or spread and to the central bank's preferences. In the example given in Figure 12, the rate of change in operation frequency is non-monotonic, complicating the determination of optimal supply.

${ }^{28}$ While the formal analysis is more complicated in this case, the logic is identical to the case with a sharp kink. 


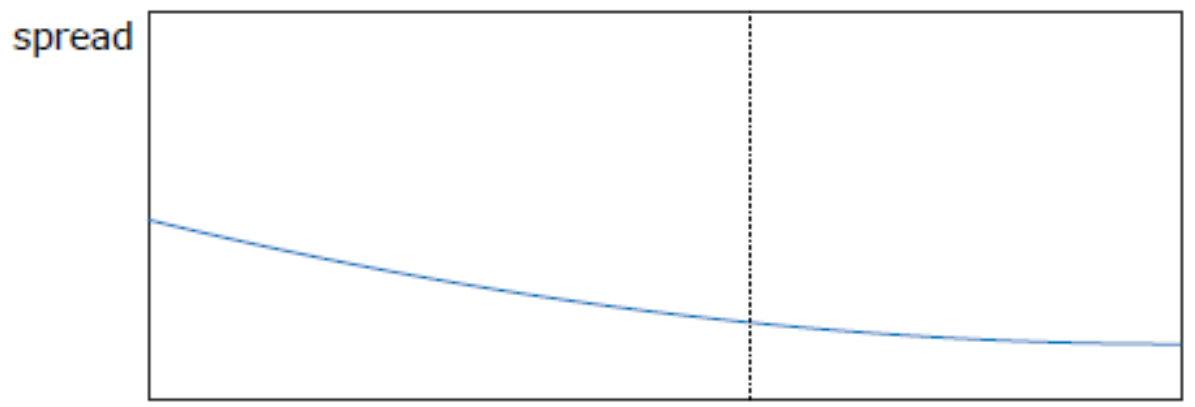

reserve supply

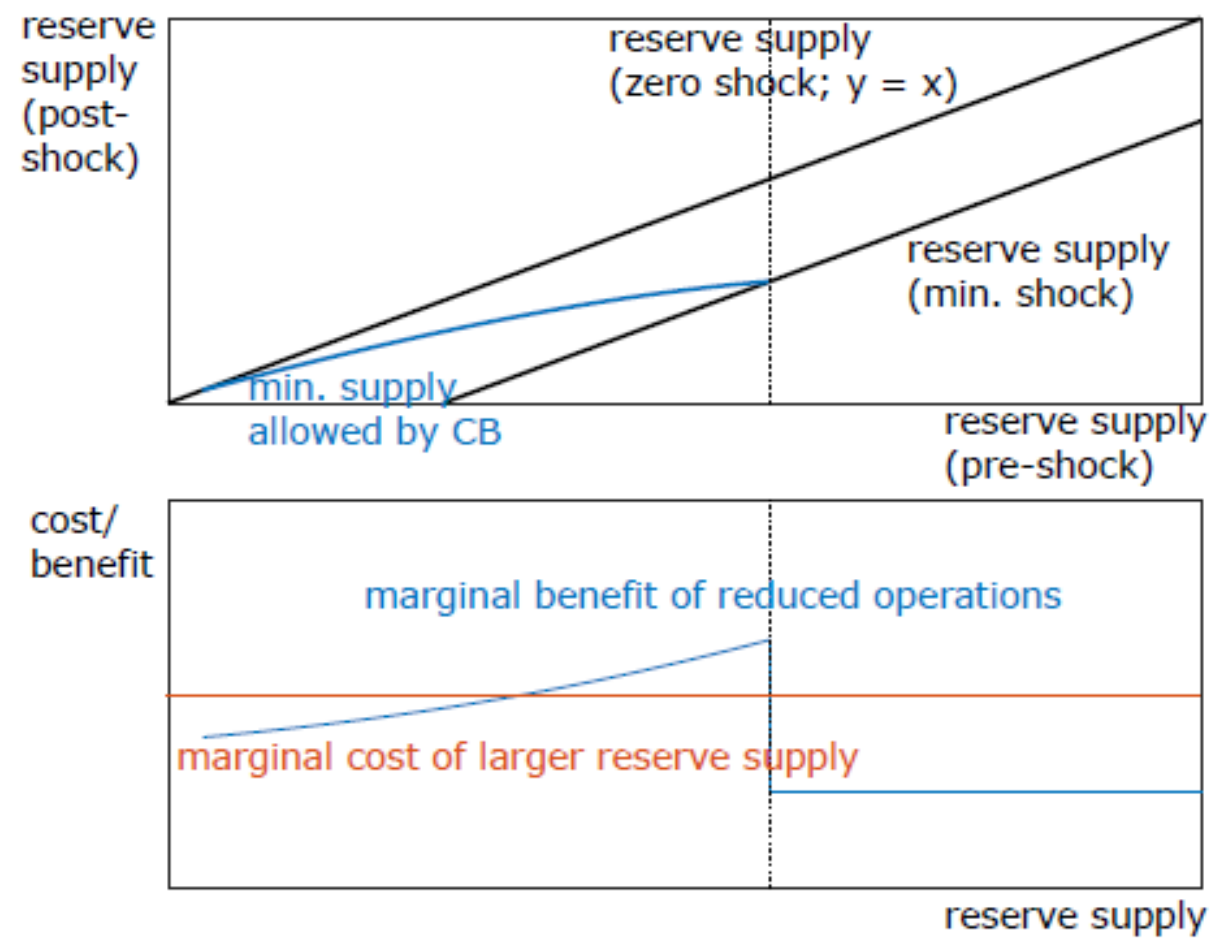

Figure 12: Implementation without a Sharp Kink.

Also, with a gradual change in the slope, the rationale for one-sided operations is less clear, because the difference in the slope when reserves are hit by a negative supply shock and when hit by a positive shock is small. In contrast, in the previous example with the standard model, the central bank will choose to conduct only reserve-injecting operations because reserve-draining operations are not necessary.

In the example with a sharp kink, it is relatively simple to take into account demand uncertainty. Since the demand shock cannot be offset preemptively, the buffer against the policy rate rising too high needs to increase by the size of the maximum demand shock. Similarly, the lowest target level of reserve supply for which operations are necessary increases by the same amount.

Without a sharp kink, the threshold similarly increases, but not by the magnitude of the maximum demand shock; the magnitude of the minimum demand shock and the target (preshock) reserve supply also matter, as the slope of spread changes gradually. Figure 13 illustrates 
the shifts in the threshold for operations, with and without a sharp kink; the panels are counterparts to the middle panels on Figure 11 and Figure 12. Because of demand uncertainty, operations become necessary at larger levels of reserve supply. On Figure 13, the central bank will keep reserve supply above the level indicated by the orange lines under demand uncertainty, and above the blue lines without demand uncertainty. The orange lines are generally located above the blue lines, due to precautionary intervention taking into account demand uncertainty.
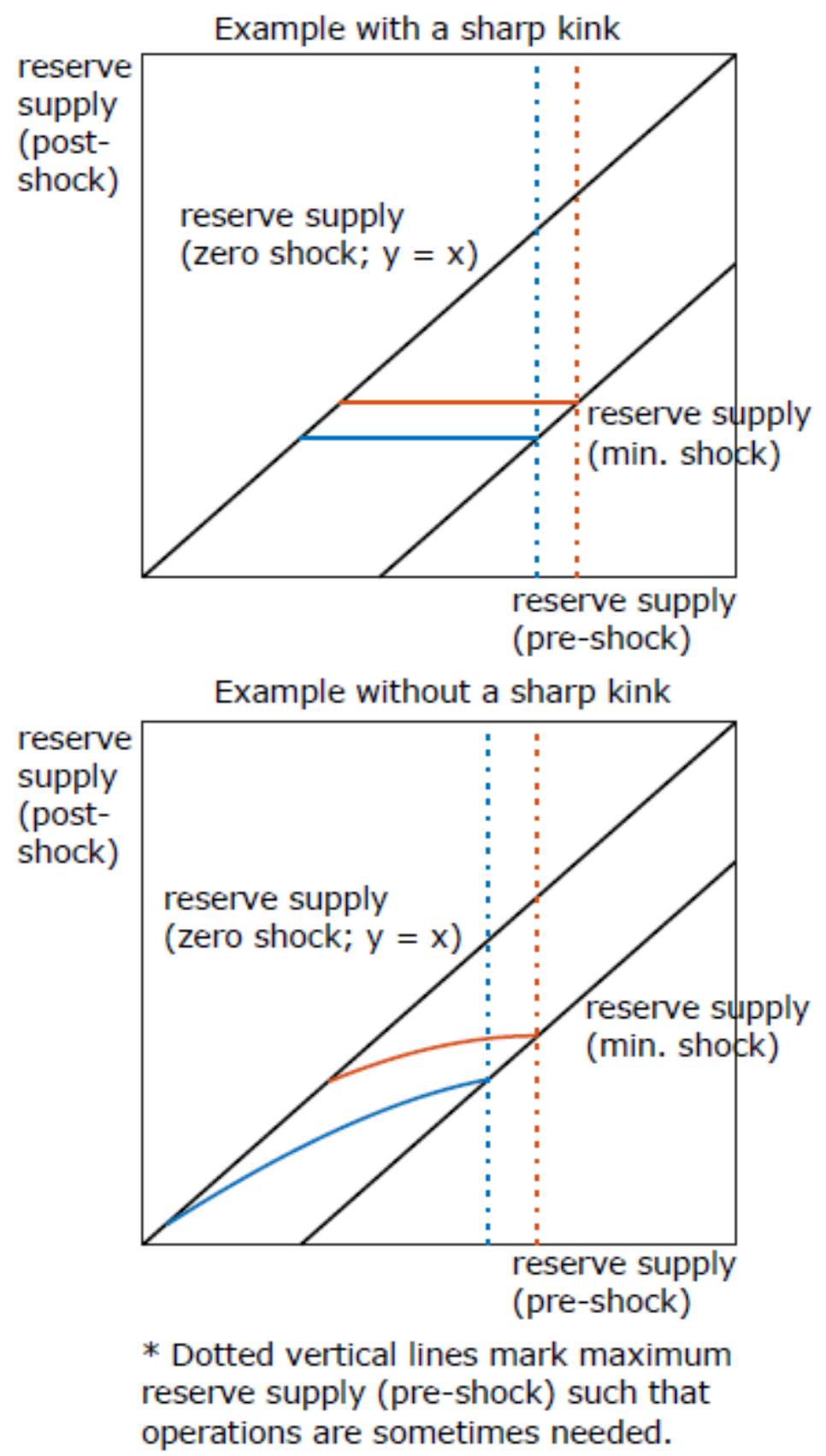

Figure 13: Implementation under Demand Uncertainty. 
In practice, the shape of the spread function is not known perfectly. This uncertainty presents a problem for a central bank trying to reduce its abundant reserve supply to reach an optimal level. The central bank can take steps to mitigate the risk, such as spending resources to learn more about the shape of the spread function or reducing reserve supply at a conservative pace, but ultimately must balance the benefits of reaching an optimal level of reserve supply against the risks of overshooting.

Optimal reserve supply without binding financial stability considerations

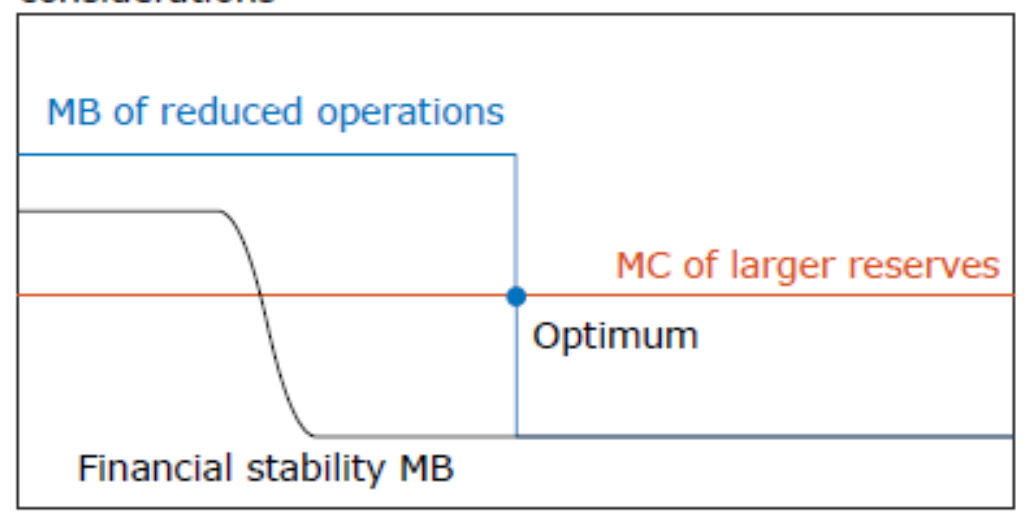

Optimal reserve supply with binding financial stability considerations

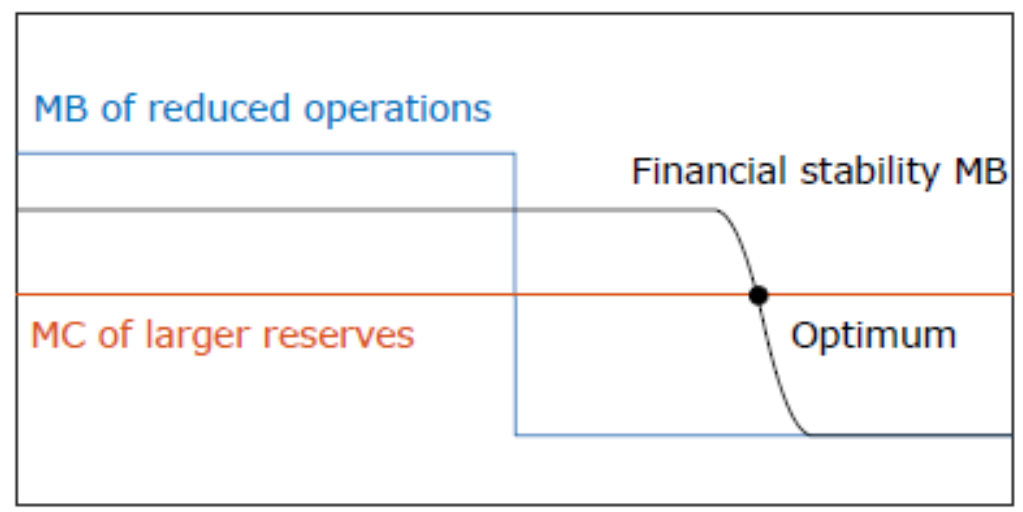

* MB is marginal benefit and MC is marginal cost.

Figure 14: Financial Stability Buffer.

Financial stability is an important element of reserve supply determination that we have mostly ignored in this section. We have generally treated a central bank as having a preference for smaller reserve supply, outside the cost of policy rate volatility and open market operations. However, in practice a central bank might prefer to maintain some buffer of reserve supply above required reserves to support financial stability, for reasons described in greater detail below. If the optimal reserve supply based on other considerations were already large enough to provide this buffer, then it would still be optimal even under added financial stability considerations. However, if the optimal supply were not large enough, then the central bank 
might decide to provide extra reserve supply to serve as a financial stability buffer. Figure 14 illustrates this.

\subsection{Mid-September 2019 Money Market Events}

In mid-September 2019, the effective federal funds rate (EFFR) sharply increased by 16 basis points over two days, printing at 2.3 percent on September 17, outside the FOMC's target range. At the same time, the supply of reserves reached the lowest level seen since the beginning of balance sheet normalization. Through the lens of the model in this paper, these events could be interpreted as the supply of reserves intersecting with the steeper part of the demand for reserves. The New York Fed's Open Market Trading Desk responded to the increase in the effective funds rate by adding reserves to the banking sector through large repo operations and, in October 2019, the FOMC announced a decision to maintain the supply of reserves at a level greater than the one that prevailed in early September.

The mid-September money market events are consistent with the case of a demand curve with a sharp kink, as illustrated by Figure 11. As the supply slowly decreases, there would be at first little or no evidence that the quantity supplied is approaching the kink in the demand curve. Then, once the kink is reached, the interest rate increase would be sharp, as was the case on September 16 and September 17. ${ }^{29}$

Our model suggests that if the kink is sharp, the central bank should supply enough reserves to avoid (almost) ever hitting the kink in the reserve demand. The Federal Reserve's October 2019 announcement could be interpreted, within the framework of our model, as consistent with this implication. ${ }^{30}$

\section{Broader Measures of Effectiveness}

The model above considers the effectiveness of the policy implementation framework only in terms of its ability to control or limit volatility in the central bank's policy rate. The policy rate performs two important roles in a monetary policy framework. The first role is communicating the stance of policy: Typically, a central bank conveys the stance of monetary policy to the public by announcing the setting of its policy rate. The second role is transmitting the stance of policy: A change in the policy rate is expected to carry through to money market rates and broader financial conditions to affect the macroeconomy.

Central banks have used a variety of interest rates as policy rates, including secured and unsecured rates, as well as market-determined and "administered" rates. The choice seems to depend on the specific institutional setting in different jurisdictions, as well as the liquidity of available markets. In practice, the distinction between market and administered policy rates is

\footnotetext{
${ }^{29}$ Of course, a number of other factors may have also played a role in the events of mid-September.

${ }^{30}$ See the operating policy announcement by the Federal Reserve Bank of New York: https://www.newyorkfed.org/markets/opolicy/operating_policy_191011.
} 
small, as central banks that choose an administered policy rate usually also refer to a market rate, either explicitly or implicitly.

But regardless of the choice of policy rate, central banks in practice typically find it desirable that short-term money market rates remain close to each other. This is especially the case in a financial system such as that of the U.S. where diverse types of institutions trade in multiple, potentially segmented markets. Although an environment with multiple money markets goes beyond the scope of our simple theoretical model, we can empirically examine the effectiveness of policy implementation in this broader sense. This section measures two dimensions of effectiveness: the extent to which different money market rates move closely together, or conversely are dispersed from each other; and the extent to which moves in IOR pass through one-for-one to various money market rates. Along both of these dimensions, we find that the Federal Reserve has maintained good control of a range of money market rates by using adjustments in administered rates, primarily IOR.

\subsection{Measurement of Effectiveness}

Duffie and Krishnamurthy (2016) create an index intended to capture rate dispersion across different segments of money markets. They consider the volume-weighted average absolute deviation from the volume-weighted average rate, which captures how much each market rate deviates from the average rate across markets. To implement the index, Duffie and Krishnamurthy adjust rates for term and credit spreads, and weight each instrument's influence by its outstanding amount. This index is designed to equal zero in a world without any frictions, where all rates yield the same adjusted return, and to be constant in a world with perfect pass-through, where all rates move in lockstep. Afonso, Biesenbach, and Eisenbach (2017) show that the implementation framework used by the Federal Reserve post crisis has achieved good pass-through.

Potter (2018) discusses a number of measures of effective control of rates. Specifically, he notes that the effective federal funds rate, the Federal Reserve's current policy rate, has remained within the FOMC's target range during the post crisis period. In fact, as shown in Figure 15, since the FOMC announced the establishment of a target range for the federal funds rate in 2008, the effective federal funds rate has printed outside the target range in only two instances. ${ }^{31}$

\footnotetext{
31 The effective fed funds rate printed below the target range on December 31, 2015 and above the target range on September 17, 2019.
} 


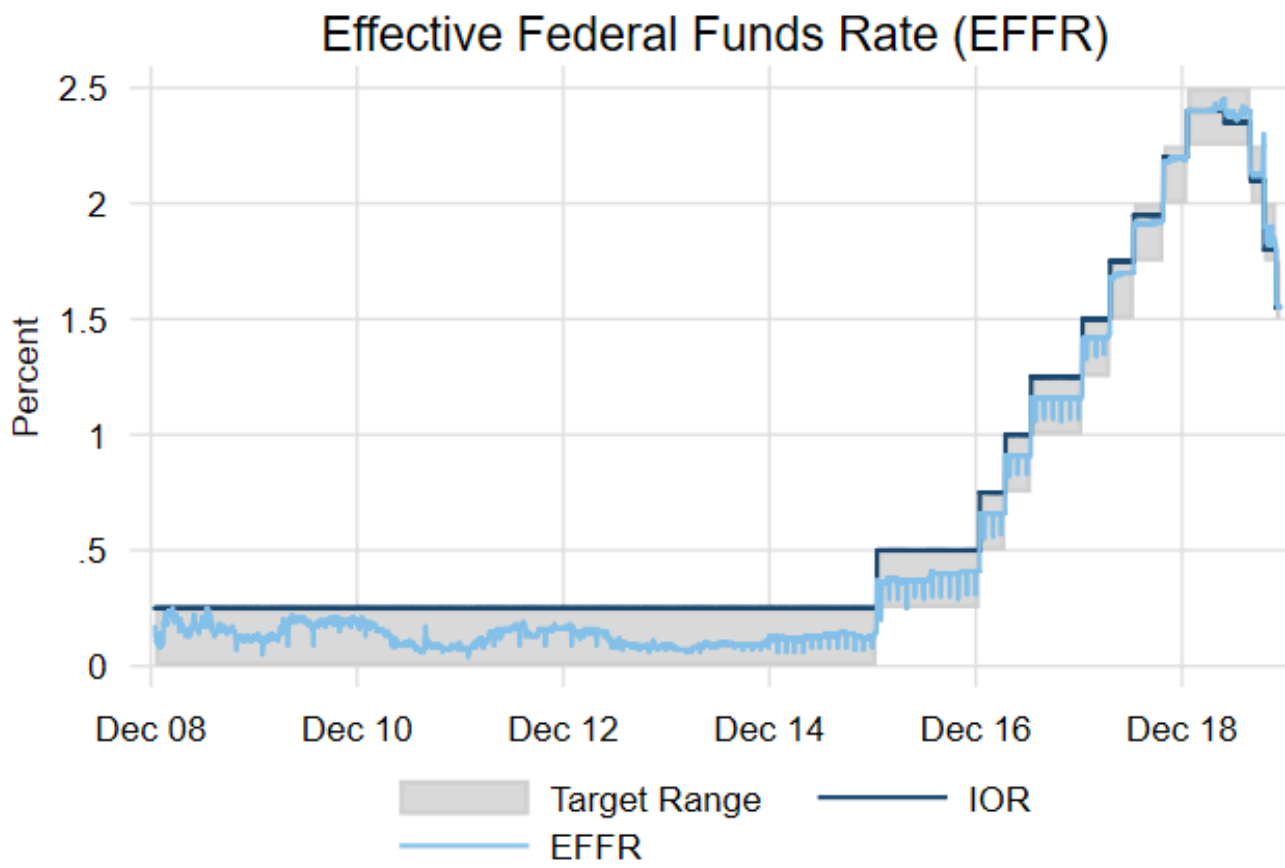

Source: Federal Reserve Bank of New York, Board of Governors

Figure 15: Effective Federal Funds Rate.

Another way of measuring the effectiveness of the operating regime is by the pass-through of administered rates to market rates. Increases in the target range for the federal funds rate have passed through fully and immediately to the other rates, as seen in Figure 16. The figure also shows that, with the exception of the September events, money market interest rates have remained close to the effective federal funds rate. 


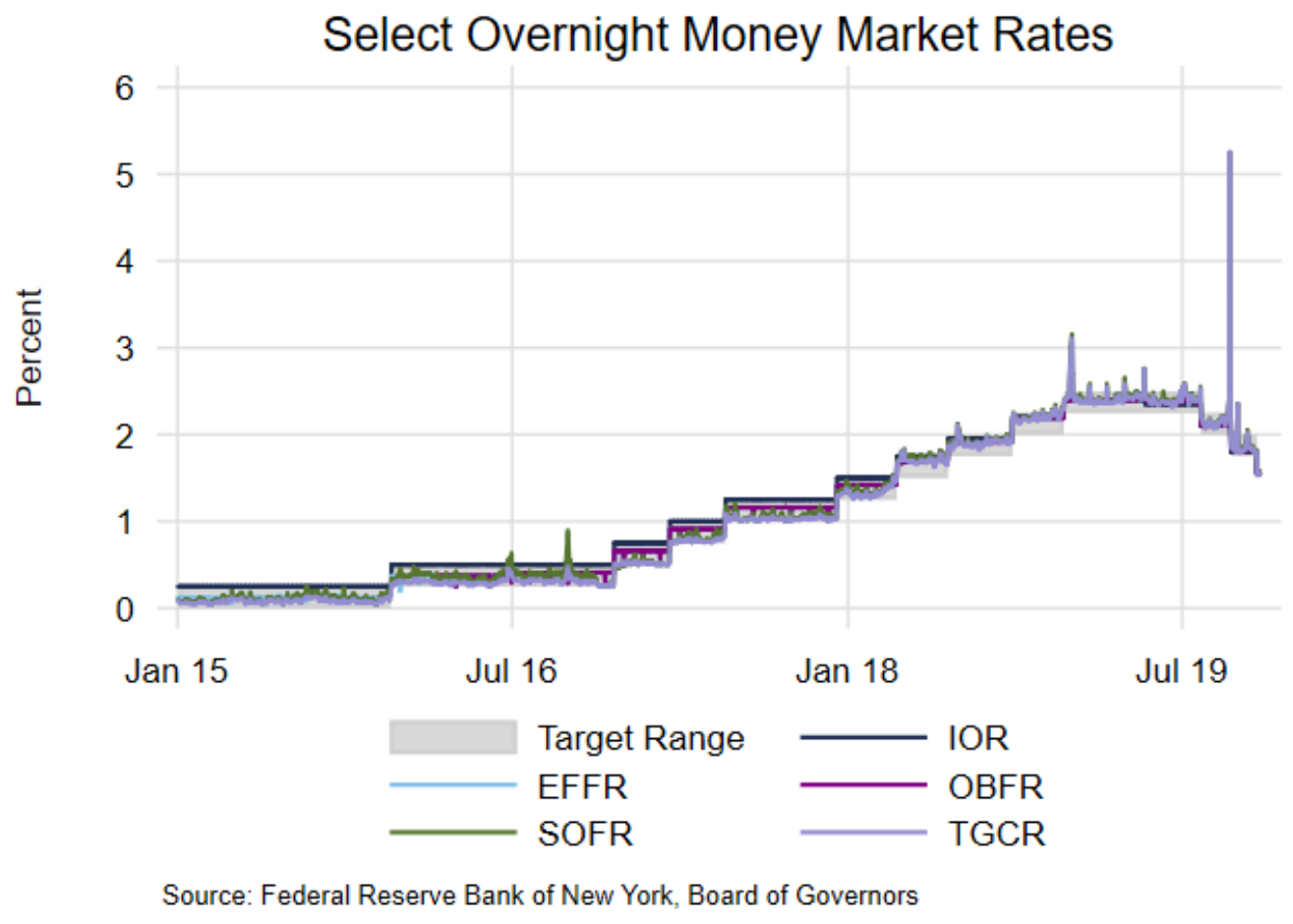

Figure 16: Overnight Money Market Rates.

\subsection{Technical Adjustments}

A particularly interesting way to look at the effectiveness of the Federal Reserve's current implementation framework is to consider the effect of the "technical adjustments" on various money market rates. During the second half of 2018, a number of money market rates increased relative to IOR. At least two factors are believed to have contributed to this increase: a decrease in the supply of reserves and a large increase in Treasury issuance (see Smith 2019, SchulhoferWohl and Clouse 2018, and Martin, McAndrews, Palida and Skeie 2019). The increase in money market rates relative to IOR led to a decision by the Federal Reserve to increase IOR by less than the increase in the policy range on two occasions, following the June and the December 2018 FOMC meetings. In each case, the target range for the federal funds rate was increased by 25 basis points and the level of the IOR was increased by only 20 basis points. Following the May 2019 meeting, the Federal Reserve announced a third technical adjustment that cut the IOR rate while keeping the policy rate unchanged. In September 2019, the Federal Reserve made the decision to implement a fourth technical adjustment by decreasing IOR by less than the decrease in the policy range. The purpose of these technical adjustments is "to foster trading in the federal funds market at rates well within" the target range (Federal Reserve 2018).

Figure 17 zooms in around the June and December 2018 and the May and September 2019 technical adjustments and shows that short-term money markets fell relative to the top of the 
target range by about 5 basis points following the technical adjustments, consistent with an effective framework (see Afonso, Ravazzolo, and Zori 2019).

\section{Changes in Interest on Reserves Pass Through to Other Overnight Rates}

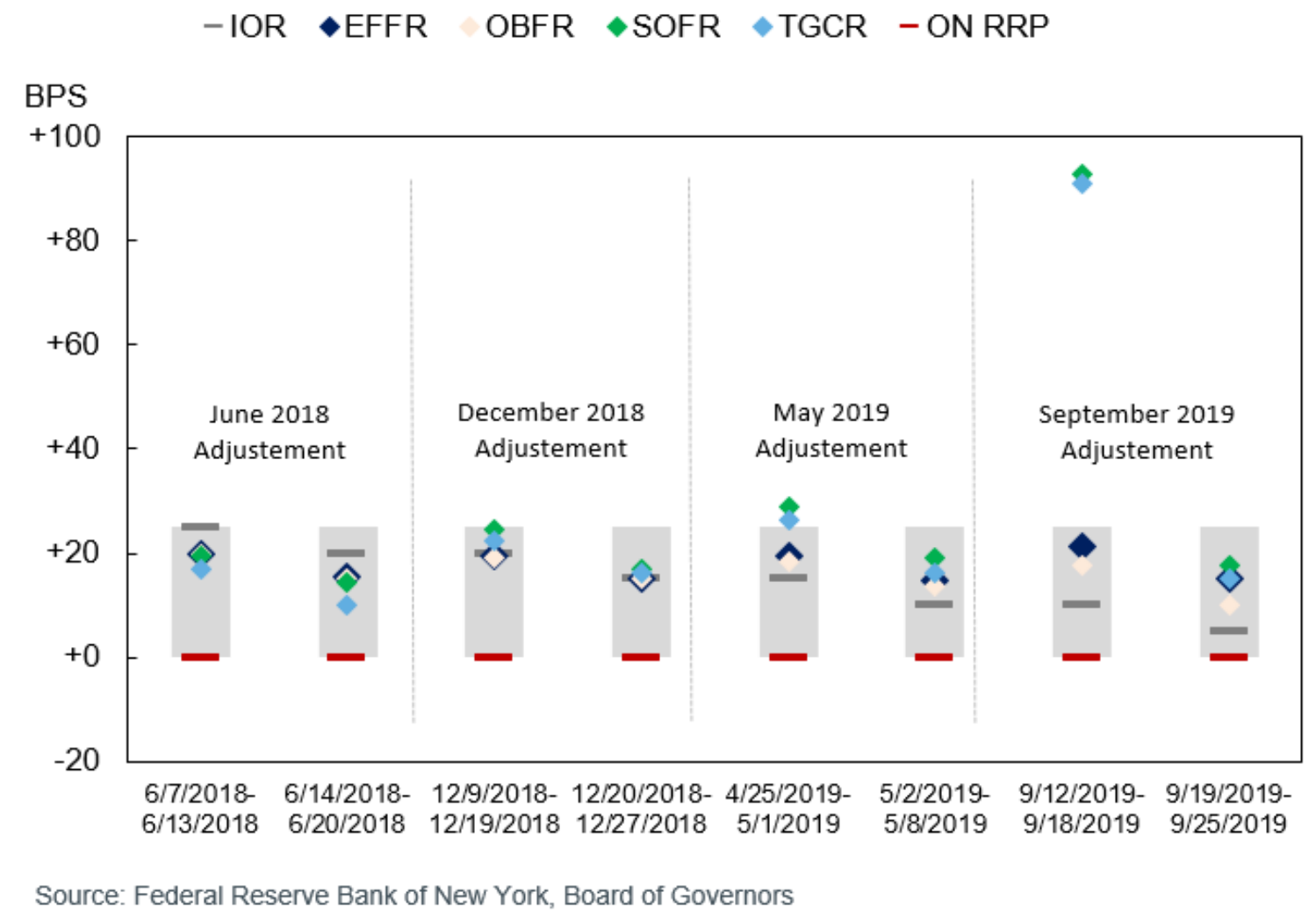

Figure 17: Technical Adjustments and Overnight Money Market Rates.

\section{Financial Stability Benefit of a Framework with an Ample Supply of Reserves}

In this section, we discuss how operating on the relatively flat part of the demand curve for reserves and with a large supply of reserves can enhance financial stability. Operating on the relatively flat part of the demand curve for reserves facilitates liquidity provision by the central bank, reduces the need for central bank intervention in times of stress, and can discourage excessive creation of private money-like assets. However, the marginal benefit of reserves for financial stability decreases as the supply increases beyond a certain point. Therefore, considerations of financial stability along with operational costs call for supplying what we have labeled ample reserves, for example in the manner described by Figure 14 earlier. 


\subsection{Facilitating Liquidity Provision to Markets}

In a framework that relies on reserve scarcity, such as the one used by the Fed pre-crisis, there can be a tension between maintaining interest rate control and providing liquidity to markets. In this section, we illustrate this tension using data about the Fed's liquidity injections during the crisis. We show how the tension is lessened when operating on the flat part of the demand curve for reserves.

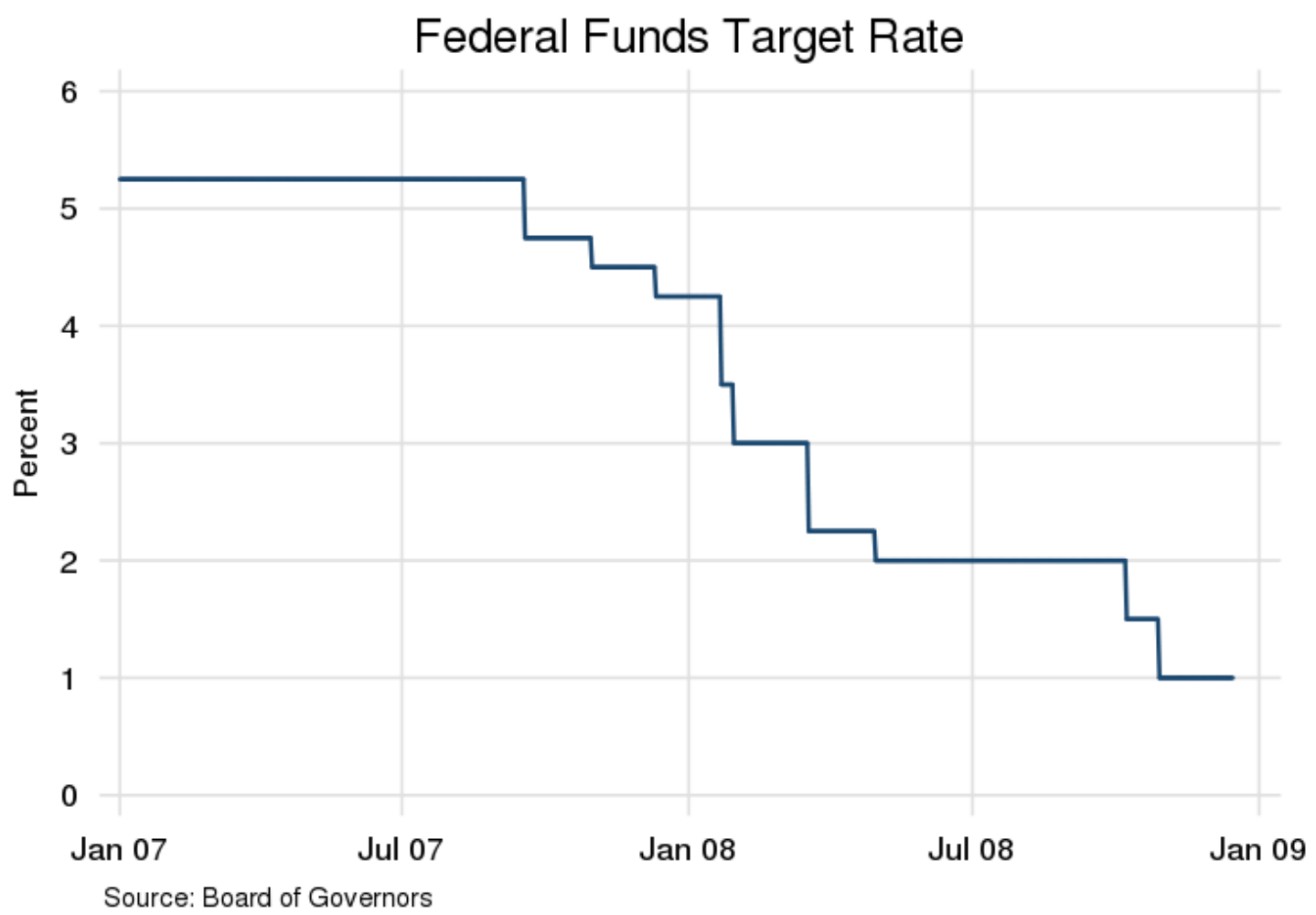

Figure 18: Federal Funds Rate Target.

Figure 18 shows the level of the federal funds rate target from January 1, 2007, to December 15, 2008. The target rate was at $5.25 \%$ until September 2007. On December 12, 2007, when the term auction facility (TAF) was announced, the target was still at $4.25 \% .{ }^{32}$ On the eve of the bankruptcy of Lehman Brothers, the target rate was $2 \%$. This meant that throughout this period, the central bank faced the trade-off between interest rate control and liquidity provision and maintaining control of the policy rate required "sterilizing" reserve injections. ${ }^{33}$ This concern

\footnotetext{
${ }^{32}$ See Armantier, Krieger and McAndrews (2008) for an overview of the TAF.

${ }^{33}$ In this context, sterilizing means that the central bank removes an amount of reserves equivalent to the amount injected so that the overall supply of reserves does not increase. Sterilized reserves injections facilitate the redistribution of reserves to the institutions that most need them without changing the total amount of reserves available.
} 
was raised in a 2007 intermeeting call of the FOMC by William C. Dudley, then manager of the System Open Market Account (SOMA), who noted, "[w]e cannot change the amount of reserves in the system if we want to keep the federal funds rate anchored at the target." 34

Figure 19 shows several Fed lending operations between January 1, 2007, and September 12, 2008, the Friday before the bankruptcy of Lehman Brothers. The two largest sources of liquidity to the market were the Term Securities Lending Facility (TSLF) and the TAF. ${ }^{35}$

Selected Federal Reserve Lending Operations

Outstanding Volumes - Weekly Averages

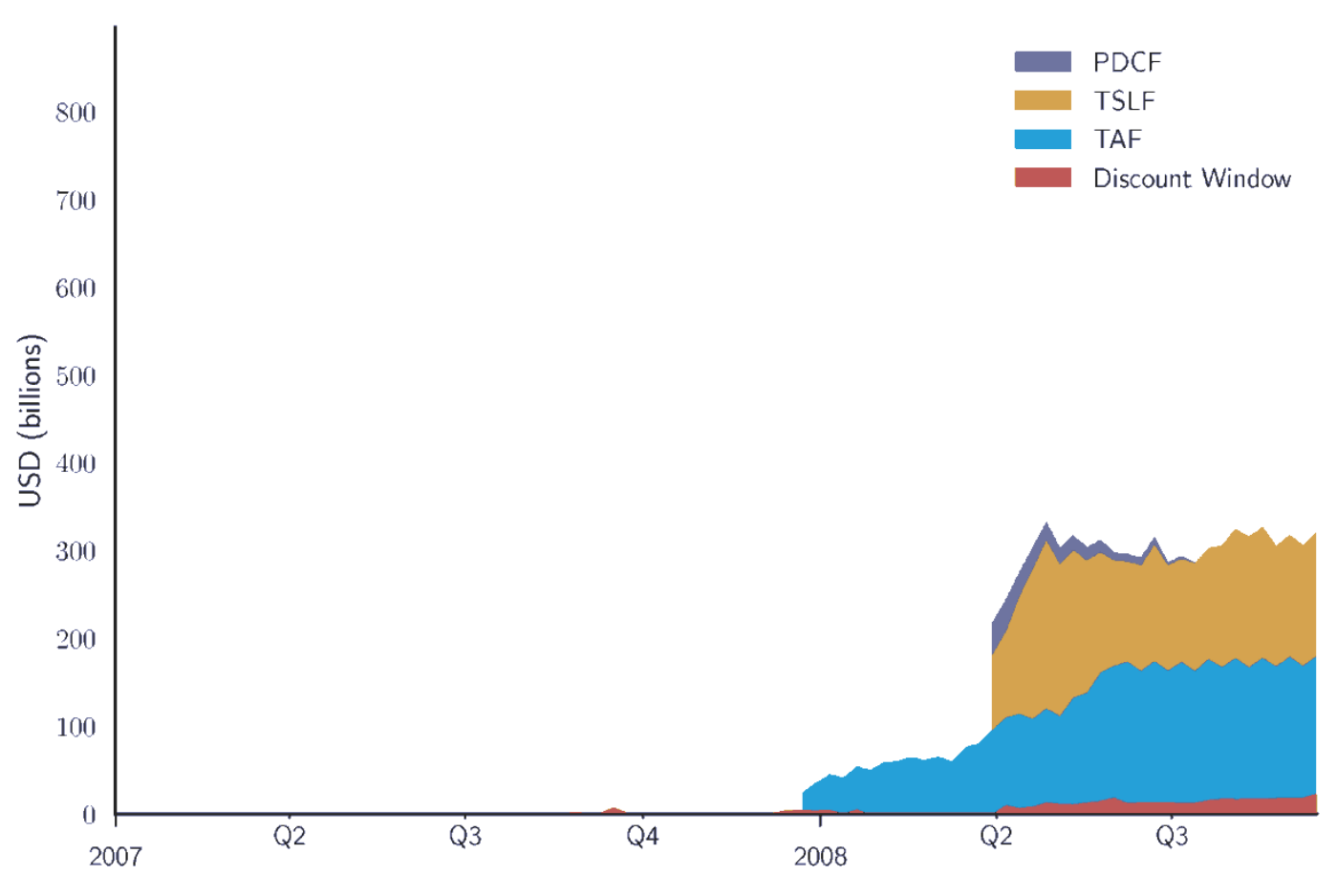

Figure 19: Federal Reserve Lending Operations.

The TSLF was a weekly loan facility that promoted liquidity in Treasury and other collateral markets and thus fostered the functioning of financial markets more generally. The program offered Treasury securities held by the SOMA for loan over a one-month term against other program-eligible general collateral. ${ }^{36}$ One benefit of the TSLF was that it did not affect the supply of reserves and, thus, did not need to be sterilized.

\footnotetext{
${ }^{34} \mathrm{https://www.federalreserve.gov/monetarypolicy/files/FOMC20071206confcall.pdf} \mathrm{(page} \mathrm{18).}$

${ }^{35}$ For more detail about the primary dealer credit facility (PDCF), see Adrian, Burke, and McAndrews (2009). More details about the discount window can be found at this link: https://www.federalreserve.gov/regreform/discountwindow.htm.

${ }^{36}$ See Fleming, Hrung, and Keane (2009) for an overview of the TSLF.
} 
The TAF auctioned 28-day loans, and, beginning in August 2008, 84-day loans, to depository institutions in generally sound financial condition. The TAF was introduced because bank funding markets, especially term funding markets, came under severe pressure at the start of the financial crisis in 2007. The TAF was useful, in part, because many banks were reluctant to borrow at the discount window out of fear that their borrowing would become known and would be erroneously taken as a sign of financial weakness. A number of design features of the TAF were specifically aimed at reducing banks' reluctance to borrow.

Everything else equal, every dollar of TAF loans increased the supply of reserves by a dollar. ${ }^{37}$ To sterilize these reserve injections, and maintain interest rate control, the Fed would let Treasury securities from its portfolio mature, instead of rolling them over. ${ }^{38}$ This can be seen in Figure 20, which represents the asset side of the Fed's balance sheet between January 1, 2007, and September 12, 2008, the Friday before the bankruptcy of Lehman Brothers.

Before the crisis, the SOMA was composed primarily of Treasury securities. The SOMA held a significant share of Treasury securities with a short time to maturity that could be allowed to roll off if it became necessary to sterilize a reserve injection. The decrease in the stock of Treasuries in the SOMA in Figure 20 corresponds to an increase in TAF loans. By the end of the second quarter of 2008, the SOMA had run out of maturing Treasury securities other than a small Treasury bill portfolio, making further sterilization of TAF loans impractical. This put an effective cap on the size of the TAF, as can be seen in Figure 19. ${ }^{39}$ This provides evidence that the need to maintain interest rate control could have put a limit on the Fed's ability to provide markets with more liquidity. ${ }^{40}$

Another program worth noting in this context is the Treasury's supplementary financing program. On September 17, 2008, the Treasury announced the program. In a statement the same day, the Federal Reserve Bank of New York noted "[t]he program will consist of a series of Treasury bill auctions, separate from Treasury's current borrowing program, with the proceeds from these auctions to be maintained in an account at the Federal Reserve Bank of New York. Funds in this account serve to drain reserves from the banking system, and will therefore offset the reserve impact of recent Federal Reserve lending and liquidity initiatives." ${ }^{41}$

\footnotetext{
${ }^{37}$ From an implementation perspective, one benefit of the TAF is that the amount auctioned was a fixed quantity, making sterilization particularly easy.

${ }^{38}$ Leonard, Martin, and Potter (2017) explain how rolling over securities, or not doing so, affects the Fed's balance sheet.

${ }^{39}$ In principle, the Fed could have sterilized reserve injections by selling Treasury securities. However, this option may not have been perceived as particularly attractive since financial markets were under stress.

${ }^{40}$ See also the response to question 4 in this FAQ: https://www.newyorkfed.org/markets/ior faq.html.

${ }^{41}$ https://www.newyorkfed.org/markets/statement 091708.html.
} 


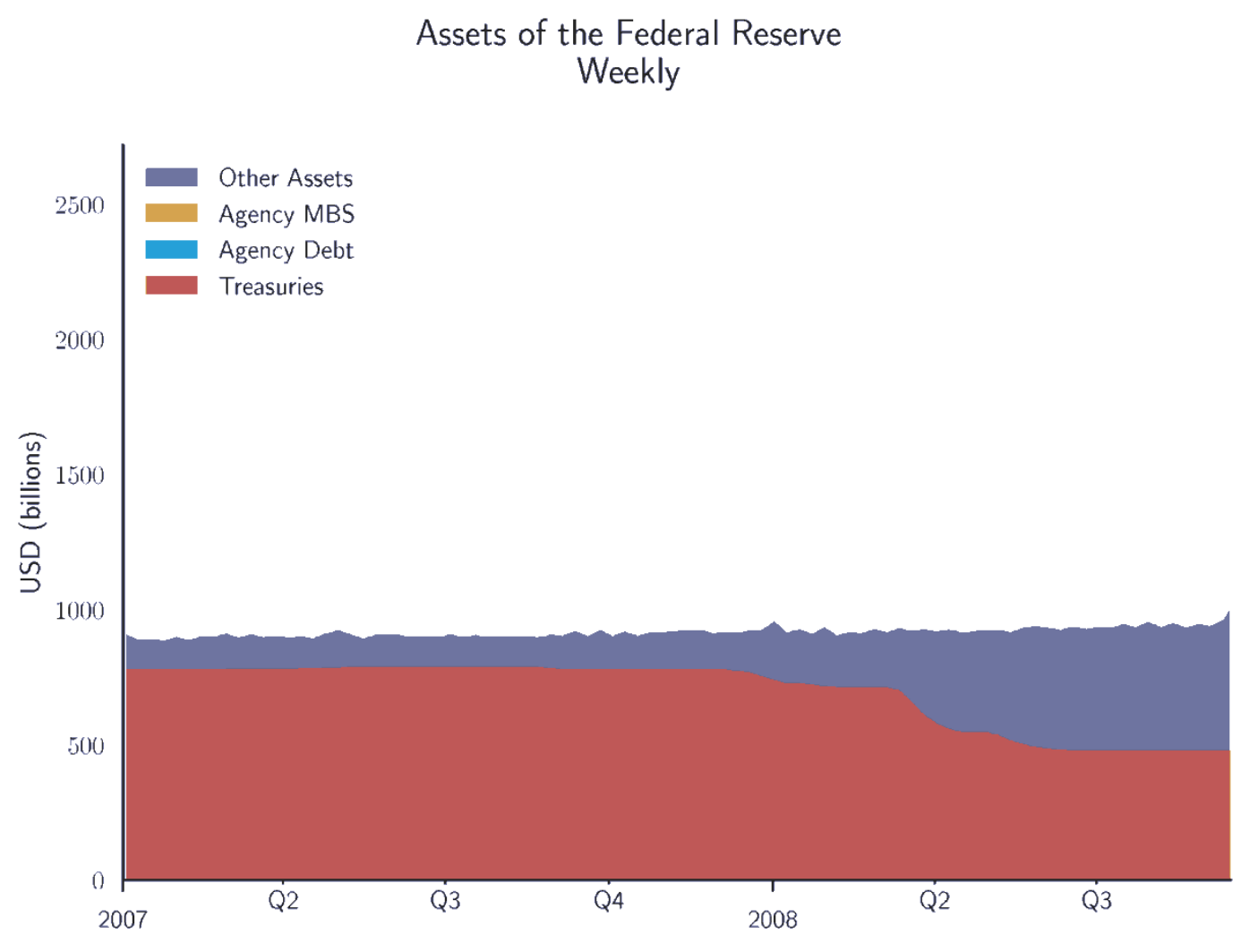

Figure 20: Federal Reserve Assets.

Further evidence is provided by considering the Fed's liquidity provision after the Lehman bankruptcy. On October 1, 2008, a couple of weeks after the bankruptcy of Lehman Brothers, the Fed received from Congress the authority to pay interest on reserves. With this new authority, reserve scarcity was no longer necessary to maintain interest rate control and the Fed was able to increase its supply of liquidity to markets considerably. Figure 21 extends Figure 19 and shows the Fed's lending operations between January 1, 2007, and December 31, 2010. The figure illustrates the striking increase in the amount of liquidity the Fed injected in financial markets, in particular in the amount of TAF lending.

By operating a monetary policy implementation regime in which control over the level of the federal funds rate and other short-term interest rates is exercised primarily through the setting of the Federal Reserve's administered rates, the Fed does not have to face a trade-off between interest rate control and liquidity provision to market during times of stress. This means that the Fed can respond more effectively to financial market stress and limit the impact of such stress on the broader economy. 
Selected Federal Reserve Lending Operations

Outstanding Volumes - Weekly Averages

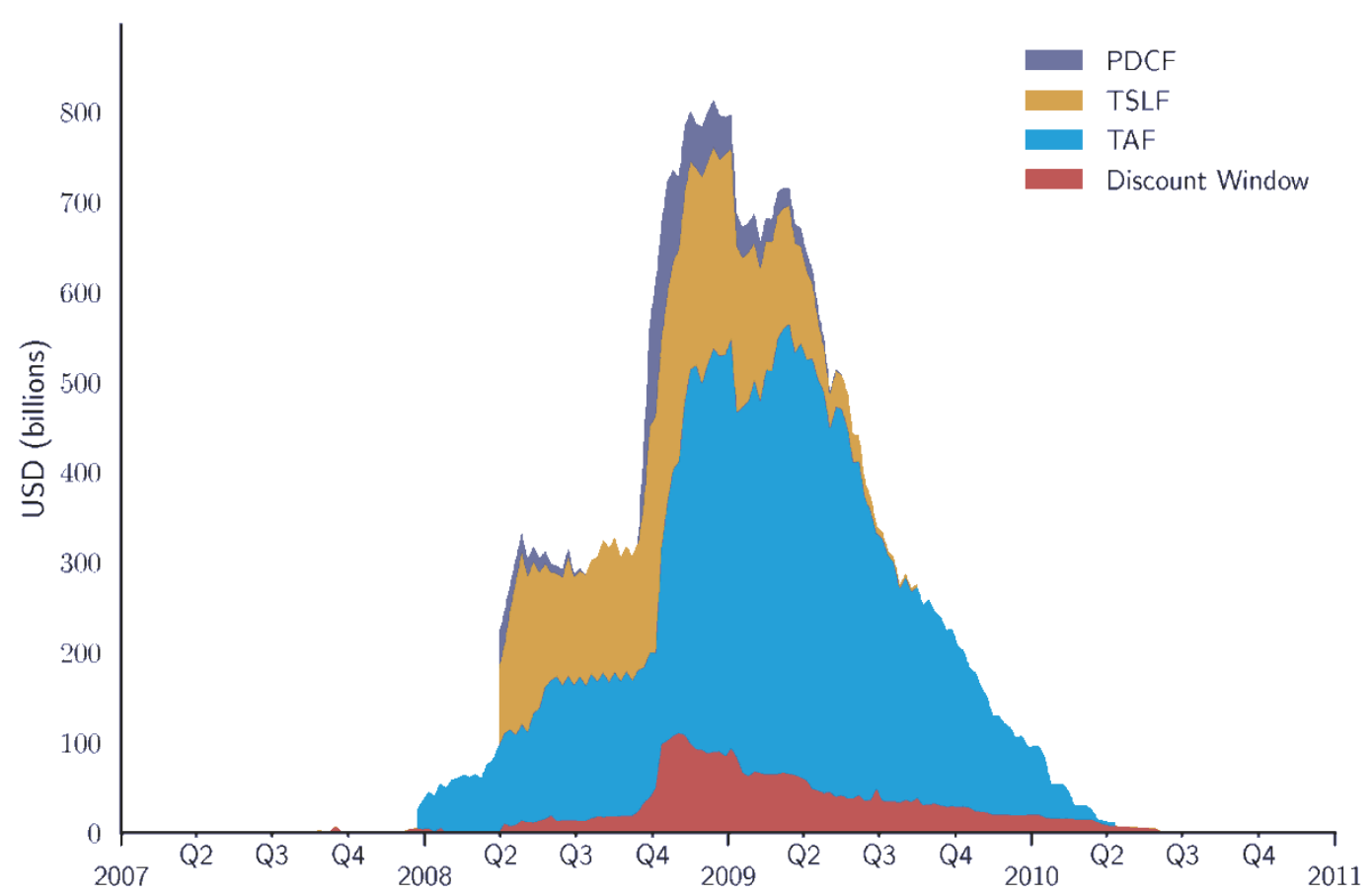

Figure 21: Federal Reserve Lending Operations.

\subsection{Supporting the Banking System's Need during Times of Stress}

While the previous section emphasized a central bank's ability to provide liquidity to markets without sacrificing interest rate control, another benefit of a system with ample reserves is that banks are better prepared to respond to financial stress, should it occur, reducing the need for central bank intervention in the first place. ${ }^{42}$

One of the responses to the 2007-2009 financial crisis was the introduction of liquidity regulation as part of the Basel III reforms, including the LCR. As noted above, the LCR requires banks to hold sufficient HQLA such as reserves and Treasury securities to meet net cash outflows over a thirty-day stress period. In addition to liquidity regulation, banks conduct internal liquidity stress tests to evaluate their liquidity needs in times of stress.

In thinking about their HQLA buffers, banks need to consider how many reserves they hold and how quickly they would be able to "monetize" securities; that is, turn them into cash. As Bush et al. (2019) write:

While assets are considered HQLA in part because they should be reasonably easy to monetize at any time of the day, rapidly turning very large quantities of assets - even

\footnotetext{
${ }^{42}$ This section draws heavily from Bush et al. (2019).
} 
Treasury securities - into cash could be challenging. One problem is operational, as it might be difficult to find counterparties willing to purchase or repo unusually large quantities of assets on the same day an outflow occurs. Another issue is that potential counterparties may perceive an attempt to monetize a large quantity of assets as a signal of stress and, in response, hold on to their cash in case they need it later. Or they might bargain aggressively if they believe that the bank is desperate to sell, causing banks to accept extremely low prices. In turn, these fire-sale prices could spill over to the broader financial system by causing related security prices to crash as well.

In contrast, reserves, because they are already cash, don't need to be monetized. So reserves are particularly useful to meet sudden outflows.

Bush et al. (2019) studied banks' potential cash needs by examining publicly disclosed LCR data for the very largest domestic banks - those whose supervision is oversee by the Federal Reserve's Large Institution Supervision Coordinating Committee. They estimated the net outflows of these banks for a period of one business day, the horizon over which it might be most difficult to liquidate large amounts of securities. Table 1 summarizes the results of their analysis for three scenarios.

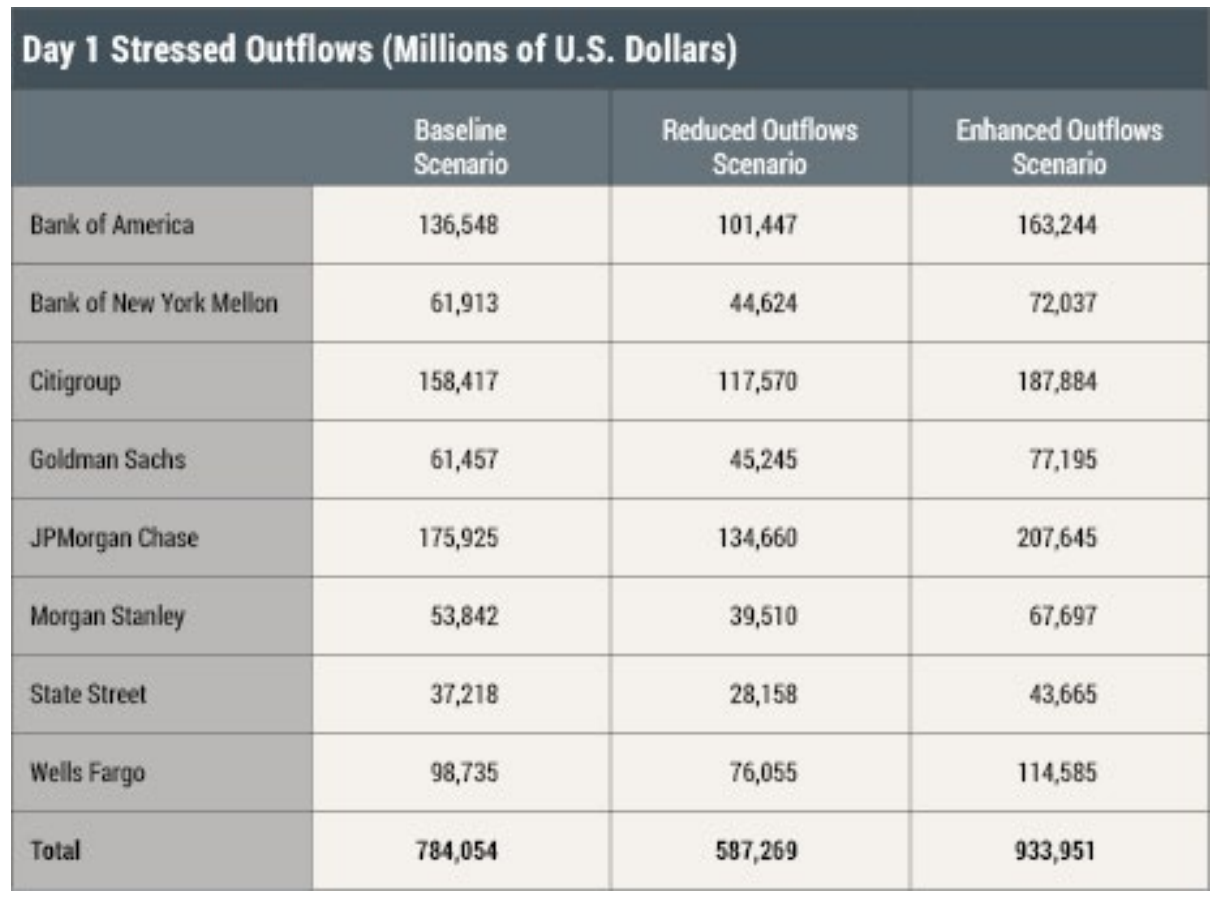

Source: Banks’ public 2018:Q2 LCR disclosures; Bush et al. (2019).

Table 1: Day 1 Stressed Outflows of LISCC firms.

Under all three scenarios, the aggregate potential outflow from domestic LISCC banks is very large, representing several hundred billions of dollars. The potential outflows of individual banks are large as well, typically tens of billions of dollars and, in a few instances, in excess of a hundred billion. As Bush et al. (2019) write, "Liquidating securities to meet such large outflows 
would likely be very difficult and could have severe negative consequences for the bank attempting to do it."

The amount of reserves available to the banking sector is primarily a choice of the Federal Reserve (see Keister and McAndrews 2009). A monetary policy implementation regime with a sufficiently large supply of reserves allows the central bank to make sure that the banking system has enough reserves for banks to meet their outflow needs during a time of stress. This makes the financial system safer and can reduce the need for banks to borrow from the central bank. ${ }^{43,44}$

\section{Conclusion}

The 2007-2009 financial crisis, and its aftermath, have led to profound changes in the way many central banks implement monetary policy. In particular, large-scale asset purchases resulted in a very large supply of reserves at major central banks, requiring these central banks to control interest rates with administered rates, using a "floor" system. Some central banks, such as the Federal Reserve, have indicated that they expect to continue using this type of implementation framework in the foreseeable future.

The results of our paper shed some light on the implications of these policy implementation decisions. In this paper, we reviewed key features of a central bank operating regime and discussed the costs and benefits of different implementation frameworks. We highlighted potential tradeoffs between the size of a central bank's balance sheet and effectiveness of rate control, as well as the frequency of central bank operations.

We provided evidence that the Federal Reserve has had good control over short-term money market rates, as measured both by dispersion across these rates and by the pass-through of administered rates to market rates, in a monetary policy implementation regime with ample reserves. Finally, we argued that financial stability concerns may make it socially efficient for the central bank to supply ample reserves rather than make reserves scarce.

\footnotetext{
${ }^{43}$ An alternative would be for the central bank to offer a liquidity facility to "monetize" Treasury securities and, perhaps, other HQLA. See Andolfatto and Ihrig (2019), for example. Such an alternative would be effective only if the liquidity facility does not suffer from stigma.

${ }^{44}$ A literature, which has developed since the 2007-2009 financial crisis, also argues that short-term safe assets, or "money-like" assets, such as reserves are particularly attractive to some investors and, for that reason, carry a premium that reduces their yield (see Carlson et al. 2016 and the references therein). When the supply of money-like assets is too small, private sector participants have an incentive to issue liabilities that have money-like properties because of their low cost. This can result in excessive maturity transformation, which makes the financial system more fragile.
} 


\section{References}

Adrian, Tobias, Christopher R. Burke, and James J. McAndrews (2009) “The Federal Reserve's Primary Dealer Credit Facility" Federal Reserve Bank of New York Current Issues in Economics and Finance 15, 4.

https://www.newyorkfed.org/medialibrary/media/research/current issues/ci15-4.pdf.

Afonso, Gara, Roc Armenter, and Benjamin Lester (2019), "A Model of the Federal Funds

Market: Yesterday, Today, and Tomorrow," Review of Economic Dynamics (33),177-204.

Afonso, Gara, Adam Biesenbach, and Thomas Eisenbach, "Mission Almost Impossible:

Developing a Simple Measure of PassThrough- Efficiency," Federal Reserve Bank of New York Liberty Street Economics (blog), November 6, 2017,

http://libertystreeteconomics.newyorkfed.org/2017/11/mission-almost-impossible-developing-asimple-measure-of-passthrough-efficiency.html.

Afonso, Gara, and Ricardo Lagos (2015), "Trade Dynamics in the Market for Federal Funds," Econometrica, Volume 83, Issue 1, pages 263-313, January 2015.

Afonso, Gara, Fabiola Ravazzolo, and Alessandro Zori, "From Policy Rates to Markets RatesUntangling the U.S. Dollar Funding Market," Federal Reserve Bank of New York Liberty Street Economics (blog), July 8, 2019, https://libertystreeteconomics.newyorkfed.org/2019/07/frompolicy-rates-to-market-ratesuntangling-the-us-dollar-funding-market.html.

Andolfatto, David, and Jane Ihrig, "Why the Fed Should Create a Standing Repo Facility" Federal Reserve Bank of St. Louis On the Economy (blog), March 62019 , https://www.stlouisfed.org/on-the-economy/2019/march/why-fed-create-standing-repo-facility.

Armenter, Roc, and Benjamin Lester (2017), "Excess reserves and monetary policy implementation," Review of Economic Dynamics (23), 212-235.

Armantier, Olivier, Sandra Krieger, and James McAndrews (2008) “The Federal Reserve's Term Auction Facility" Federal Reserve Bank of New York Current Issues in Economics and Finance 14, 5. https://www.newyorkfed.org/medialibrary/media/research/current issues/ci14-5.pdf.

Bech, Morten L., Antoine Martin, and James McAndrews (2012) "Settlement Liquidity and Monetary Policy Implementation-Lessons from the Financial Crisis” Federal Reserve Bank of New York Economic Policy Review 18, 1.

Bush, Ryan, Adam Kirk, Antoine Martin, Phil Weed, and Patricia Zobel (2019) "Stressed Outflows and the Supply of Central Bank Reserves," Federal Reserve Bank of New York Liberty Street Economics (blog), February 20, 2019, https://libertystreeteconomics.newyorkfed.org/2019/02/stressed-outflows-and-the-supply-ofcentral-bank-reserves.html.

Carlson, Mark, Burcu Duygan-Bump, Fabio Natalucci, Bill Nelson, Marcelo Ochoa, Jeremy Stein, and Skander Van den Heuvel (2016) "The Demand for Short-Term, Safe Assets and 
Financial Stability: Some Evidence and Implications for Central Bank Policies.” International Journal of Central Banking 12 (4): 307-333

Duffie, Darrell, and Arvind Krishnamurthy (2016) "Passthrough Efficiency in the Fed's New Monetary Policy Setting." Jackson Hole Symposium of the Federal Reserve Bank of Kansas City. https://www.kansascityfed.org/ /media/files/publicat/sympos/2016/econsymposium-duffiekrishnamurthy-paper.pdf

Fleming, Michael J., Warren B. Hrung, and Frank M. Keane (2009) “The Term Securities Lending Facility: Origin, Design, and Effects" Federal Reserve Bank of New York Current Issues in Economics and Finance 15, 2. https://www.newyorkfed.org/medialibrary/media/research/current_issues/ci15-2.pdf.

Federal Reserve (2018) Implementation Note issued June 13, 2018: https://www.federalreserve.gov/newsevents/pressreleases/monetary20180613a1.htm.

FOMC (2016) Minutes of the Federal Open Market Committee, November 1-2, 2016: https:/www.federalreserve.gov/monetarypolicy/files/fomcminutes20161102.pdf.

Garratt, Rodney, Antoine Martin, and James McAndrews, "Turnover in Fedwire Funds Has Dropped Considerably since the Crisis, but It's Okay," Federal Reserve Bank of New York Liberty Street Economics (blog), August 25, 2014, https://libertystreeteconomics.newyorkfed.org/2014/08/turnover-in-fedwire-funds-has-droppedconsiderably-since-the-crisis-but-its-okay.html

Greenwood, Robin, Samuel Hanson, and Jeremy C. Stein (2015) “A Comparative-Advantage Approach to Government Debt Maturity." Journal of Finance 70 (4): 1683-1722.

Keister, Todd, and James J. McAndrews (2009) "Why Are Banks Holding So Many Excess Reserves?" Federal Reserve Bank of New York Current Issues in Economics and Finance 15, 8. https://www.newyorkfed.org/medialibrary/media/research/current_issues/ci15-8.pdf.

Kim, Kyungmin, Antoine Martin, and Ed Nosal (forthcoming) "Can the US Interbank Market be Revived?" Journal of Money, Credit, and Banking.

Smith, A. Lee (2019) "Do Changes in Reserve Balances Still Influence the Federal Funds Rate?" Federal Reserve of Kansas City Economic Review.

Leonard, Deborah, Antoine Martin, and Simon Potter, "How the Fed Changes the Size of Its Balance Sheet," Federal Reserve Bank of New York Liberty Street Economics (blog), July 10, 2017, http://libertystreeteconomics.newyorkfed.org/2017/07/how-the-fed-changes-the-size-ofits-balance-sheet.html.

Logan, Lorie K. (2017) "Implementing Monetary Policy: Perspective from the Open Market Trading Desk." Remarks before the Money Marketeers of New York University, New York City: https://www.newyorkfed.org/newsevents/speeches/2017/log170518.

Martin, Antoine, James McAndrews, Ali Palida, and David Skeie (2019) "Federal Reserve Tools for Managing Rates and Reserves.” Federal Reserve Bank of New York Staff Reports, 642. 
Potter, Simon (2018) "U.S. Monetary Policy Normalization is Proceeding Smoothly." https://www.newyorkfed.org/newsevents/speeches/2018/pot181026

Schulhofer-Wohl, Sam, and James Clouse (2018) "A Sequential Bargaining Model of the Fed Funds Market with Excess Reserves.” Federal Reserve Bank of Chicago working paper 2018-08. 